\title{
AN ALTERNATIVE DISJUNCTIVE OPTIMIZATION MODEL FOR HEAT INTEGRATION WITH VARIABLE TEMPERATURES
}

Miguel A. Navarro-Amorós ${ }^{a}$, José A. Caballero ${ }^{a}{ }^{a}$, Rubén Ruiz-Femenia $^{\mathrm{a}}$, Ignacio E. Grossmann ${ }^{\mathrm{b}}$

${ }^{a}$ Department of Chemical Engineering, University of Alicante., Ap Correos 99, 03080, Alicante, Spain

${ }^{b}$ Department of Chemical Engineering, Carnegie Mellon University, 5000 Forbes Av. 15213. Pittsburgh, PA USA.

\begin{abstract}
This paper presents an alternative model to deal with the problem of optimal energy consumption minimization of non-isothermal systems with variable inlet and outlet temperatures. The model is based on an implicit temperature ordering and the "transshipment model" proposed by Papoulias \& Grossmann (1983). It is supplemented with a set of logical relationships related to the relative position of the inlet temperatures of process streams and the dynamic temperature intervals. In the extreme situation of fixed inlet and outlet temperatures, the model reduces to the "transshipment model". Several examples with fixed and variable temperatures are presented to illustrate the model's performance.
\end{abstract}

Keywords: Heat Integration, Disjunctive model, MILP, MINLP, Logic Disjunctions.

\section{INTRODUCTION}

A major concern of the chemical process industry is energy consumption. Energy consumption and raw materials together usually constitute the main contribution to the total cost of a product. To address this problem there has been an important development in process integration in parallel to the continuous evolution of the technologies for improving process plant design. Therefore, the key to increasing the economic benefits and efficiency of a plant involve minimizing energy consumption and energy losses, and increasing energy efficiency.

The first approaches for process integration were based on heuristic methods. The practical implementation of heuristic methods relies on a set of rules derived from both, first principles and designer's experience for creating and screening process alternatives. These heuristic concepts were progressively integrated into other methods (e.g. graphical and thermodynamic insights), and were finally systematized by different researchers, resulting in what is known today as conceptual design (J. M. Douglas, 1985; J.M. Douglas, 1988; R. Smith, 2005; Robin Smith \& Linnhoff, 1988).In its more basic form the problem is decomposed into a set of levels of increasing detail. For example, Douglas (J. M. Douglas, 1985; J.M. Douglas, 1988) proposed decomposing the problem into five levels: 1 . Batch vs. Continuous, 2. Input Output structure, 3. Recycle structure, 4. Gas and Liquid Separation and 5. Heat integration. These levels were extended by Smith (2005) to include waste disposal, water networks, environmental considerations, etc. 
The main limitation of this sequential approach is that decisions in the outer levels constrain the alternatives in the most inner levels. The simultaneous design of reaction - separation and heat integration can significantly improve process performance. The reaction can have a large impact on both raw materials and energy usage (in most cases mainly on raw material consumption).The separation, depending on what the conversion and/or selectivity are, can also have a great impact on raw material consumption (e.g. the non-reacted feed is very difficult to separate), as well as on energy. And finally heat integration has a major impact on energy consumption. In this paper our focus is on latter.

Continually increasing energy costs has forced chemical and petrochemical companies to find new ways of decreasing energy consumption by improving especially heat exchanger networks. The first researchers to introduce the concept of heat integration were Linnhoff and Flower in 1978 (Linnhoff \& Flower, 1978a). They developed the concept of pinch analysis whose initial objective was to determine the minimum utilities requirements of a process, and to identify the best possible degree of heat recovery achievable as a function of the minimum temperature difference inside the heat exchanger network. In 1983, Linnhoff and Hindmarsh (Linnhoff \& Hindmarsh, 1983) demonstrated that it is possible to save a significant part of all the energy required by a plant.

Since those initial developments, there has been rapid growth in the field of heat integration. An excellent review with annotated bibliography can be found in the work by Furman and Sahinidis (Furman \& Sahinidis, 2002). Moreover, Morar and Agachi (2010a) presented a comprehensive review of heat integration techniques.

Among all the techniques that have been developed for heat integration, there are two main approaches: Pinch Analysis, and the Mathematical Programming based models (Morar \& Agachi, 2010b). Because of its simplicity, pinch analysis is the more widely used technique, since it can be easily applied by hand even to large problems. It has demonstrated efficiency and applicability in many problems on industrial energy-savings. Pinch analysis can be divided into three steps (Ahmad et al., 1990; Linnhoff \& Ahmad, 1990; Linnhoff \& Flower, 1978a, 1978b; Linnhoff \& Hindmarsh, 1983):

1. Given a minimum heat recovery approach temperature (HRAT), generate by graphical or tabular means the hot and cold composite curves and read in the minimum utilities for the entire system. It is also possible to determine which among all the available utilities are the most adequate, using the Grand Composite curve.

2. Estimate the minimum number of heat exchangers

3. Estimate the total area and total cost (or synthesize the net by using heuristic rules).

4. Repeat steps 1 to 3 using different values of HRAT until the minimum cost of the net is obtained. 
Methods based on mathematical programming initially followed a sequential approach, imitating the pinch analysis: determination of minimum utilities, which takes the form of a transshipment LP model (Soterios A. Papoulias \& Ignacio E. Grossmann, 1983), or a transportation LP model (Cerda \& Westerburg, 1983); determination of the minimum number of heat exchangers that can be formulated as a Mixed Integer Linear Programming Problem (MILP); and finally, generation of the actual heat exchangers network, which is an NLP problem (Floudas et al., 1986).

While the sequential targeting and optimization approach have the advantage of decomposing the synthesis problem into smaller problems, it has the disadvantage that the trade-offs among energy, number of units and area are not rigorously taken into account. The reason for is that the optimization problem:

min: Area Cost + Fixed cost units + Utility Cost

is approximated by a problem that can be stated conceptually as follows (Biegler et al., 1997):

min: Area Cost

s.t. min: Number of Units

$$
\text { s.t. Minimum utility cost }
$$

To avoid the limitations of the sequential approach, different researchers proposed instead simultaneous approaches to solving the problem. For example, Floudas and Ciric (1989) used a superstructure based approach (they called hyper-structure), formulated as a MINLP problem, to simultaneously optimize the number of heat exchangers and the investment cost. Later, Ciric and Floudas (1991) extended the hyper-structure to the optimization of the total annual cost of the network (simultaneous optimization of utilities and investment costs). However, the most successful simultaneous model is probably due to Yee \& Grossmann (Yee \& Grossmann, 1990; Yee et al., 1990a, 1990b). The model is based on a superstructure composed of a set of stages in which each hot stream can exchange heat with all the cold streams; the mixture of streams at the end of each stage is assumed to be isothermal. Although this model does not possess some of the additional features present in other simultaneous methods, it performs better numerically because the non-linearities are only in the objective function while the constraints are all linear. Substantial improvements have been achieved and reported when simultaneous models were used instead of sequential ones (Biegler et al., 1997)

All the methods discussed thus far assume that the inlet and outlet temperatures are fixed and known a priori. In other words, the heat integration is performed only after all the process operation conditions have been fixed. But it is known that the simultaneous optimization of the process conditions and heat integration can result in important savings in total cost (Duran \& Grossmann, 1986b). Including the detailed design of the heat exchanger network (HEN) in the detailed process optimization tends to produce large non-convex MINLP problems. However, if we assume that the dominant cost associated with the HEN is the energy, and that the inlet and 
outlet temperatures could also have a synergistic effect on the rest of the process, it is justified to simultaneously optimize the process operating conditions (specifically including the stream temperatures) and the cost of external hot and cold utilities that result from maximum heat integration.

As far as we know, the only research dealing with simultaneous optimization and heat integration - focusing on process and energy cost minimization but not including the design of HEN - are due to Duran \& Grossmann (1986b) and Grossmann et al (1998). However, a number of special models have been developed for specific applications, e.g. Floudas and Paules (1988) or Raman and Grossmann (1993),for heat integration in distillation systems, adapted later by Caballero and Grossmann $(1999,2006)$ to complex systems. Taking into account that the pinch point coincides with the inlet temperature of any of the hot or cold streams, and assuming constant heat capacity flowrates, these authors showed that the criteria for selecting the correct pinch - corresponding to minimum feasible heating and cooling involved selecting among all the pinch candidates the one that exhibited the largest heating and cooling (Pinch Location Method). In that way Duran and Grossmann (1986c) did not need the concept of "Temperature interval" to locate the pinch point. The final mathematical formulation results in a non-differentiable optimization problem (due to the max operators that appear in the model). Initially, a smooth approximation was proposed to solve the problem. Later, Grossmann et al (1998) proposed a rigorous disjunctive formulation of the "pinch location method" that uses logic disjunctions to explicitly model the relative placement of streams for various potential pinch locations, and explicitly considers the non-isothermal and isothermal streams as separate cases.

In this paper we propose an alternative model for simultaneous optimization and heat integration, which retains the concept of temperature interval with which many designers are familiar due to the prevalence of the pinch technology. The basic idea is to perform an implicit ordering of all the temperatures; in that way the temperature intervals are also implicitly defined, and the 'classical' equations for the transshipment (Soterios A. Papoulias \& Ignacio E.

Grossmann, 1983) can be easily incorporated in the model.

\section{PROBLEM STATEMENT}

We address the following problem. Given:

- A superstructure of alternative process flowsheets.

- A set $\mathrm{n}_{\mathrm{H}}$ of hot process streams to be cooled and a set $\mathrm{n}_{\mathrm{C}}$ of cold process streams to be heated.

- The available utilities, their temperatures, and their costs per unit of heat (provided or removed) 
determine the optimal process flowsheet that minimizes the utility cost.

The flowrates, inlet and outlet temperatures for all these process streams are not fixed, and must therefore be optimized.

We will assume that the heat flow rates of the hot and cold process streams are constant, and that the inlet and outlet temperatures are bounded by upper and lower limits. We formulate this minimum cost problem as a linear disjunctive programming problem and rewrite it as a MILP with the aid of a Hull Reformulation (HR). The nonlinearities that appear are due to the remaining equations describing the process, but not to those specifically related with the heat integration. In the next section a comprehensive description of the model is presented.

\section{SIMULTANEOUS HEAT AND PROCESS OPTIMIZATION: MODEL FORMULATION}

As in the models presented by Duran \& Grossmann (1986b) and Grossmann et al (1998), we implicitly assume that the simultaneous optimization and heat integration strategy, together with the dominant energy cost, yield important economic benefits despite the fact that the investment costs related to the HEN are not taken into account. A fixed Heat Recovery Approach Temperature (HRAT) must be assumed, and therefore it must be optimized in an outer loop using a targeting approach or a detailed design of the network.

With all these points in mind, we introduce the following index sets for the proposed model:

$\mathrm{ST}: \quad k: k$ is a stream

HOT: $i: i$ is a hot stream

COLD: $j: j$ is cold stream

HU: $\quad I: I$ is a hot utility

CU: $\quad j: j$ is a cold utility

TI: $\quad$ w: $w$ is a temperature interval

The set ST $(S T=H O T \cup C O L D)$ is an ordered set formed by the $n_{H}$ hot streams followed by the $\mathrm{n}_{\mathrm{C}}$ cold streams.

From a conceptual point of view the model can be written as an MINLP problem of the following structure: 


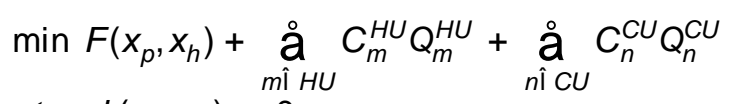

$$
\begin{aligned}
& \text { s.t. } h\left(x_{p}, x_{h}\right)=0 \\
& g\left(x_{p}, x_{h}\right) £ 0 \\
& A x_{h} \in b \\
& Q_{m}^{H U}, Q_{n}^{C U} \hat{\imath} R^{+}, m \text { î } H U, n \text { î } C U \\
& x_{h} \hat{\imath} R^{n}, x_{p} \hat{\imath} R^{n}
\end{aligned}
$$

where $Q_{m}^{H U}$ and $Q_{n}^{C U}$ are the heat load of hot utility $m$ and cold utility n, respectively, and $C_{m}^{H U}$ and $C_{n}^{C U}$ are the unit cost of hot utility $\mathrm{m}$ and cold utility $\mathrm{n}$, respectively.

The vector variable $x_{p}$ represents process parameters such as pressures, flowrates, equipment sizes, etc., and structural parameters usually represented by 0-1 binary variables. The vector variable $x_{h}$ represents the flowrates and temperatures of the process streams that undergo either cooling or heating, and also the binary variables relating to energy integration used in the model equations.

The vectors of constraint $h$ and $g$ represent the material and energy balances, design specifications or structural relationships in the synthesis problem. The linear equations $A x_{h} £ b$ are used specifically for the heat integration presented in the next section.

The model is composed of three different parts: in the first, all inlet temperatures of the system are implicitly ordered; in the second, the heat exchange is calculated for each stream in each temperature interval; and in the third, the previously calculated heat exchanges of each interval are connected in descending order via the transshipment model.

\subsection{Implicit ordering of temperatures}

The first step involves implicitly ordering the temperatures that determine the temperature intervals. It is worth noting that under the assumption of constant heat capacity flowrates, the pinch point always appears between an inlet temperature of a hot or a cold stream and any temperature of a cold or a hot stream, respectively. Therefore, we need only consider inlet temperatures when calculating the pinch point or temperature intervals.

Working with the actual temperatures leads to a pinch point that separates the hot composite curve and the cold composite curve by a temperature interval that exactly equals the value of HRAT . If we decrease the temperature of the hot streams by HRAT / 2 and increase the temperature of the cold streams by HRAT / 2, then we can obtain a pinch point that corresponds to a single temperature instead of an interval:

$$
T_{H}^{\text {in }}=T_{H}^{*, i n}-H R A T / 2
$$




$$
\begin{aligned}
& T_{H}^{\text {out }}=T_{H}^{*} \text {,out }- \text { HRAT } / 2 \\
& T_{C}^{\text {in }}=T_{C}^{*, \text { in }}+\text { HRAT } / 2 \\
& T_{C}^{\text {out }}=T_{C}^{*} \text {,out }+ \text { HRAT } / 2
\end{aligned}
$$

where $T_{H}^{\text {in }}$ and $T_{H}^{\text {out }}$ are the shifted inlet and outlet temperatures for the hot streams, $T_{C}^{\text {in }}$ and $T_{C}^{\text {out }}$ are the corresponding shifted inlet and outlet temperatures for the cold streams, and the superscript '*' denotes an actual temperature. The shifted temperatures must be constrained to lie within lower and upper bounds:

$$
\begin{aligned}
& \underline{T_{H}^{*}, i n}-H R A T / 2 £ T_{H}^{i n} £ \overline{T_{H}^{*}, i n}-H R A T / 2 \\
& \overline{T_{H}^{*} \text { out }}-H R A T / 2 \notin T_{H}^{\text {out }} £ \overline{T_{H}^{*} \text { out }}-H R A T / 2 \\
& \overline{T_{C}^{*, i n}}+\text { HRAT / } 2 £ T_{C}^{i n} £ \overline{T_{C}^{*}, i n}+\text { HRAT / } 2 \\
& \overline{T_{C}^{*} \text {,out }}+\text { HRAT / } 2 £ T_{C}^{\text {out }} £ \overline{T_{C}^{*} \text {,out }}+\text { HRAT / } 2
\end{aligned}
$$

It is also convenient to define an auxiliary temperature that stores the inlet temperatures of all the streams:

$$
T_{k}^{i n}=\left\{\begin{array}{l}
\grave{j} T_{H i}^{i n}, \text { if } k=i \\
T_{C i}^{i n}, \text { if } k=n_{H}+j \quad k=1,1 / 4, n_{H}, 1 / 4, n_{H}+n_{C}
\end{array}\right.
$$

In equation (8) the indices $k, i, j$ are ordered sets and also denote position inside their respective sets.

The sorted temperatures correspond to a permutation of the positions of the actual temperatures in the set of streams ST; the set of variables $T_{k \Phi}^{\text {ord }}$ store the sorted values of all the inlet temperatures in descending order. We accomplished this with the aid of the definition of the Boolean variable $Y_{k, k}$, which is true if the inlet temperature in position $k$ occupies position $k ₫$ after the ordering, and false otherwise.

The disjunctive model is formulated as follows:

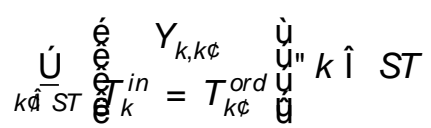

$$
\begin{aligned}
& \underset{k^{\prime} \hat{U} S T}{U} Y_{k, k^{\prime}} " k \hat{\imath} S T \\
& { }_{k i ̂}^{U} \hat{U} S T Y_{k, k^{\prime}} " k^{\prime} \hat{\imath} S T
\end{aligned}
$$




$$
T_{k-1}^{\text {ord } 3} T_{k}^{\text {ord }} " k \backslash\{1\} \hat{I} S T
$$

Equation (9) assigns to the ordered temperature $k \$$ the value of the initial temperature $k$. The equations in (10) assign a fixed position to an ordered temperature, implying that a given ordered position can only be occupied by one stream at a time. Equation (11) forces the descending ordering of temperatures.

Equations (9) and (10) can be reformulated in terms of binary variables (in this paper we use capital letters for the Boolean and small letters for the binary variables). The binary variable takes value 1 if the Boolean variable is True and 0 otherwise. The HR formulation for the disjunctions in Eq. (9) is:

$$
\begin{aligned}
& T_{k, k 屯}^{i n, D}=T_{k \nsubseteq k}^{\text {ord,D }} \quad " k \notin, a ̈ S T \\
& T_{k}^{i n}=\underset{k \llbracket \ddot{a} S T}{\stackrel{̊}{a}} T_{k, k \Phi}^{i n, D} \quad " k \text { ä } S T \\
& T_{k^{\Phi}}^{\text {ord }}=\underset{k a ̈ S T}{\stackrel{\circ}{a}} T_{k \nsubseteq k}^{o r d, D} \quad " k \Phi a ̈ ~ S T
\end{aligned}
$$

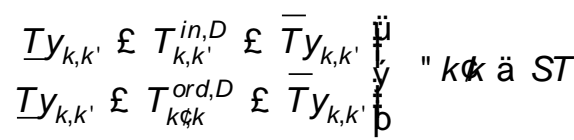

where each of the two variables $T_{k}^{i n}$ and $T_{k \mathbb{\Phi}}^{\text {ord }}$ appearing in the terms of disjunction $k$ are disaggregated into $n_{C}+n_{H}$ new variables, $T_{k, k \Phi}^{i n, D}$ and $T_{k \uparrow, k}^{\text {ord,D }}$ as described by equations (13) and (14). In Eq. (15), we use upper and lower bounds and binary variables $y_{k, k^{\prime}}$ to force the disaggregated variables $T_{k, k \uparrow}^{i n, D}, T_{k \notin k}^{\text {ord,D }}$ to zero when the initial temperature $k$ is not assigned to the ordered temperature $k \Phi$.

The assignment logic propositions, Eq.(10),are written into algebraic form using binary variables, as follows:

$$
\begin{aligned}
& \text { å } y_{k, k^{\prime}}=1 \text { " } k \hat{\imath} S T \\
& \underset{k^{\prime} \hat{I} S T}{k^{\prime} S T} y_{k, k^{\prime}}=1 \text { "k' } k^{\prime} S T
\end{aligned}
$$

Once the temperatures have been sorted, the ordered inlet temperatures (together with the maximum and minimum possible temperatures, $T^{\max }$ and $T^{\min }$, respectively) define the temperature intervals (Figure 1). The total number of temperature intervals $(\mathrm{NI})$ is equal to the number of hot streams plus the number of cold streams plus one. 


\section{FIGURE 1}

Each interval is characterized by its upper $\left(T_{w}^{U P}\right)$ and lower $\left(T_{w}^{L O}\right)$ temperatures as follows:

$$
\begin{aligned}
& T_{1}^{U P}=T_{\max } \\
& T_{w+1}^{U P}=T_{k}^{\text {ord }}, w, k=1, \mathrm{~K}, n_{H}+n_{C} \\
& T_{w}^{L O}=T_{k}^{\text {ord }}, w, k=1, \mathrm{~K}, n_{H}+n_{C} \\
& T_{N I}^{L O}=T_{\min }
\end{aligned}
$$

\subsection{Heat transfer within each temperature interval.}

For a given temperature interval and a given stream, two cases arise where the stream does not exchange heat in that interval. The first case occurs when the temperature interval is above the inlet temperature for a hot stream or the outlet temperature for a cold stream (cases $\mathrm{H} 2$ and $\mathrm{C} 1$ in Figure 2). The other case of no heat exchange occurs when the temperature interval is below the outlet temperature for a hot stream or the inlet temperature for a cold stream (cases $\mathrm{H} 1$ and $\mathrm{C} 2$ in Figure 2). We must explicitly take into account these two alternatives.

A given stream can interchange heat within a certain interval in two ways. For a hot stream, if the outlet temperature of the stream is below the lower temperature of the interval, then this stream transfers heat throughout the whole interval (case H3 in Figure 2). Alternatively, if the outlet temperature of the hot stream is greater than the lower temperature of the interval, the stream exchanges heat only in a part of the interval (case H4 in Figure 2). Similarly, a cold stream transfers heat throughout the entire interval if its outlet temperature is higher than the upper temperature of the interval (case $\mathrm{C} 3$ in Figure 2). Likewise if the outlet temperature of the cold stream is lower than the upper temperature of the interval, then this stream exchanges heat only in a part of the interval (case C4 in Figure 2).

\section{FIGURE 2}

To model these alternatives, we write the linear disjunctions (18) and (19), which require definition of the following Boolean variables:

$Z_{i, w}^{H} \quad$ True if the hot stream i exchanges heat in the temperature interval $w$.

$Z_{i, w}^{C} \quad$ True if the cold stream $\mathrm{j}$ exchanges heat in the temperature interval $\mathrm{w}$.

$Z_{i, w}^{H 1} \quad$ True if the inlet temperature of the hot stream $i$ is below the temperature of interval $w$

$Z_{i, w}^{H 2} \quad$ True if the outlet temperature of the hot stream $i$ is above the temperature interval $w$ 
$Z_{i, w}^{H 3} \quad$ True if the hot stream $i$ traverses the temperature interval $w$

$Z_{i, w}^{H 4} \quad$ True if the outlet temperature of the hot stream $i$ is inside the temperature interval $w$

$Z_{j, w}^{C 1} \quad$ True if the outlet temperature of the cold stream $j$ is below the temperature interval $w$

$Z_{j, w}^{C 2} \quad$ True if the inlet temperature of the cold stream $j$ is above the temperature interval $w$

$Z_{j, w}^{C 3} \quad$ True if the cold stream $j$ traverses the temperature interval $w$

$Z_{j, w}^{C 4} \quad$ True if the outlet temperature of the cold stream $j$ is inside the temperature interval $w$

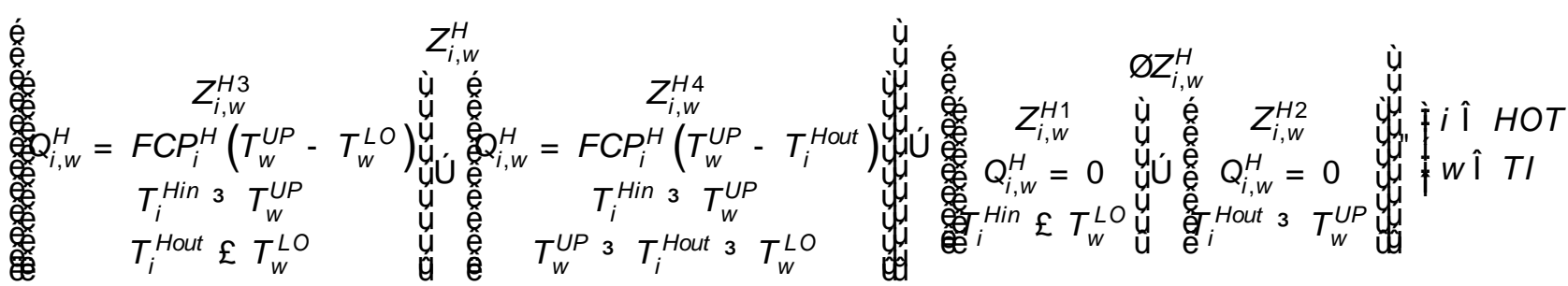

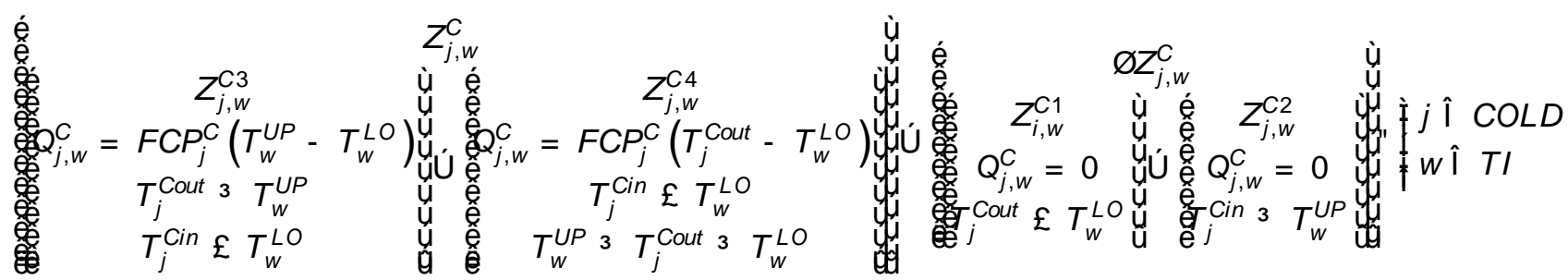

In disjunctions (18) and (19) it is assumed that heat flow rates $F C P_{i}^{H}, F C P_{j}^{C}$ are known and constant (it is possible to include the heat flow rates as variables, but in this case the problem becomes bilinear). $Q_{i, w}^{H}$ and $Q_{j, w}^{C}$ are the heat flows exchanged by hot and cold streams in the interval $w$, respectively.

Furthermore, a complete description of the alternatives demands making use of the following logical expressions:

$$
\begin{aligned}
& Z_{i, w}^{H} \text { Û } Z_{i, w}^{H 3} \cup ́ Z_{i, w}^{H 4}, \quad i \text { î HOT,wî TI } \\
& \varnothing Z_{i, w}^{H} \hat{U} Z_{i, w}^{H 1} \underline{u} Z_{i, w}^{H 2} \text { "iî HOT; "wî TI } \\
& Z_{j, w}^{C} \hat{U} \quad Z_{j, w}^{C 3} \underline{U} Z_{j, w}^{C 4} \text { "jî } \operatorname{Col} D ; \text { " wî } T I
\end{aligned}
$$




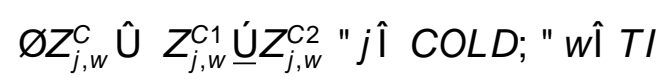

Disjunctions (18) and (19) can be rewritten in terms of binary variables with the aid of HR. For the hot streams Eq. (18) the reformulation reads as follows:

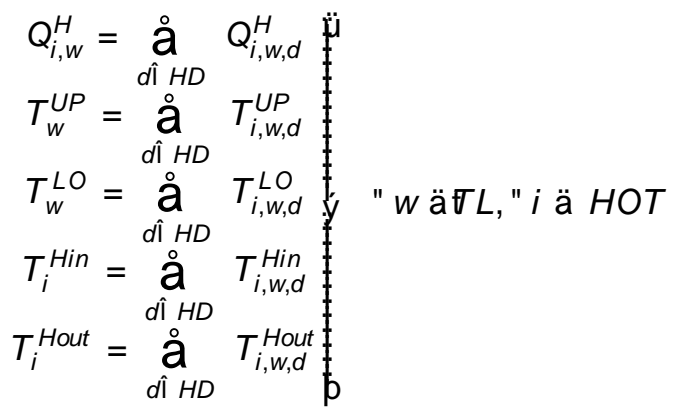

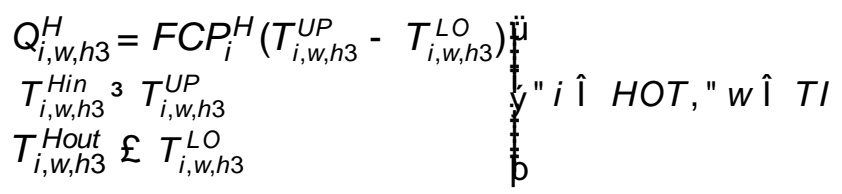

$$
\begin{aligned}
& Q_{i, w, h 4}^{H}=F C P_{i}^{H}\left(T_{i, w, h 4}^{U P}-T_{i, w, h 4}^{\text {Hout }}\right) \ddot{\ddot{i}} \\
& T_{i, w, h 4}^{H i n}{ }^{3} T_{i, w, h 4}^{U P} \\
& T_{i, w, h 4}^{\text {Hout }} £ T_{i, w, h 4}^{U P} \\
& T_{i, w, h 4}^{\text {Hout }}{ }^{3} T_{i, w, h 4}^{L O} \\
& \text { "y } i \text { î HOT, "wî TI } \\
& \begin{array}{l}
Q_{i, w, h 1}^{H}=0 \\
T_{i, w, h 1}^{H i n} £ T_{i, w, h 1}^{L O} \ddot{y}^{\prime} i \text { î HOT, " } w \hat{\imath} ~ T I
\end{array}
\end{aligned}
$$

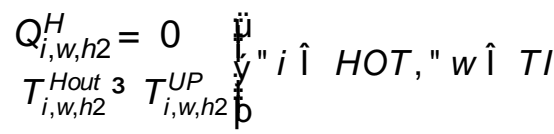

$$
\begin{aligned}
& Q_{i, w, d}^{H} £ \overline{Q_{i}} Z_{i, w}^{d} \\
& \underline{T_{w}} z_{i, w}^{d}{ }^{3} \quad T_{i, w, d}^{U P} £ \overline{T_{w}} z_{i, w}^{d} \\
& \underline{T}_{w} Z_{i, w}^{d}{ }^{3} \quad T_{i, w, d}^{L O} £ \overline{T_{w}} Z_{i, w}^{d} \\
& \underline{T_{i}^{H i n} Z_{i, w}^{d}{ }^{3}} T_{i, w, d}^{H i n} £ \overline{T_{i}^{H i n}} Z_{i, w}^{d} \\
& {\underline{T_{i}^{\text {Hout }}}}_{Z_{i, w}^{d}}{ }^{3} T_{i, w, d}^{\text {Hout }} £ \overline{T_{i}^{\text {Hout }} Z_{i, w}^{d}}
\end{aligned}
$$

HR requires introducing disaggregated variables for $Q_{i, w}^{H}, T_{w}^{U P}, T_{w}^{L O}, T_{i}^{H i n}$, and $T_{i}^{\text {Hout }}$, which we label with subscript $d$, the index of the set $H D=\{H 1, H 2, H 3, H 4\}$ (Eq. (24)). In Eq. (29), an upper and lower bound is assigned to each disaggregated variable, so that when $z_{i, w}^{d}=1$ the variables can take values between these bounds, and if $z_{i, w}^{d}=0$ then 
$Q_{i, w, d}^{H}=T_{i, w, d}^{U P}=T_{i, w, d}^{L O}=T_{i, w, d}^{H i n}=T_{i, w, d}^{\text {Hout }}=0$. Note that the bounds for the disaggregated variables, those variables which define the temperature interval $w$ (that is $T_{w}^{U P}$ and $T_{w}^{L O}$ ), depend on the interval itself.

Similarly, for the cold streams:

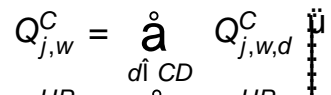

$$
\begin{aligned}
& T_{w}^{U P}=\stackrel{d i}{\stackrel{O}{a}} T_{j, w, d}^{U P}
\end{aligned}
$$

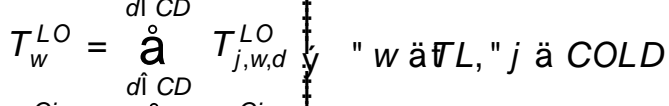

$$
\begin{aligned}
& T_{j}^{C i n}=\stackrel{\circ}{a} T_{\text {di CD }}^{\text {Cin }}
\end{aligned}
$$

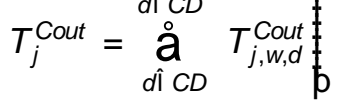

$$
\begin{aligned}
& Q_{j, w, C 3}^{C}=F C P_{j}^{C}\left(T_{j, w, C 3}^{U P}-T_{j, w, C 3}^{L O}\right) \ddot{\ddot{i}} \\
& T_{j, w, C 3}^{\mathrm{Cin}}{ }^{3} T_{j, w, C 3}^{U P} \\
& T_{j, w, C 3}^{\text {Cout }} \notin T_{j, w, C 3}^{L O} \\
& \text { "y } \\
& Q_{j, w, c 4}^{C}=F C P_{j}^{C}\left(T_{j, w, C 4}^{U P}-T_{j, w, c 4}^{\text {Cout }}\right) \ddot{\ddot{H}} \\
& T_{j, w, C 4}^{\text {Cin }}{ }^{3} T_{j, w, C 4}^{U P} \\
& T_{j, w, C 4}^{\text {Cout }} £ T_{j, w, C 4}^{U P} \\
& T_{j, w, C 4}^{\text {Cout }}{ }^{3} T_{j, w, C 4}^{L O} \\
& \text { "j î COLD, "wî TI }
\end{aligned}
$$

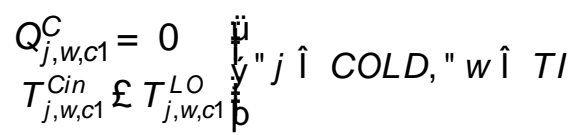

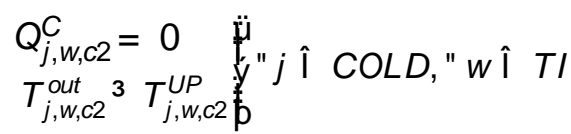

$$
\begin{aligned}
& Q_{j, w, d}^{C} £ \overline{Q_{j}} Z_{j, w}^{d} \\
& \underline{T_{w} Z_{j, w}^{d}{ }^{3}} \quad T_{j, w, d}^{U P} £ \overline{T_{w}} z_{j, w}^{d} \\
& T_{w} z_{j, w}^{d}{ }^{3} T_{j, w, d}^{L O} £ \overline{T_{w}} z_{j, w}^{d} \quad \bar{y} " j \hat{\imath} \operatorname{COLD}, \text { " wî } T \text { I } \\
& T_{j}^{C i n} Z_{j, w}^{d}{ }^{3} T_{j, w, d}^{\operatorname{Cin}} £ \overline{T_{j}^{C i n}} Z_{j, w}^{d} \\
& \underline{T_{j}^{\text {Cout }}} Z_{j, w}^{d}{ }^{3} T_{j, w, d}^{\text {Cout }} £ \overline{T_{j}^{\text {Cout }}} Z_{j, w}^{d}
\end{aligned}
$$

where, analogously to the hot case, we define the set $C D=\{C 1, C 2, C 3, C 4\}$ to achieve disaggregation of the variables.

Finally, the logical expressions (20)-(23) are converted into linear inequality constraints as follows: 


$$
\begin{aligned}
& z_{i, w}^{h}=z_{i, w}^{h 3}+z_{i, w}^{h 4} \text { "i î HOT, " } w \hat{\imath} T I \\
& \text { 1- } z_{i, w}^{h}=z_{i, w}^{h 1}+z_{i, w}^{h 2} \text { "i î HOT, "wî TI } \\
& z_{j, w}^{c}=z_{j, w}^{c 3}+z_{j, w}^{c 4} \quad " j \hat{\imath} \operatorname{COLD}, \quad \text { " } w \hat{\imath} T I \\
& \text { 1- } z_{j, w}^{c}=z_{j, w}^{c 1}+Z_{j, w}^{c 2} " j \hat{\imath} \operatorname{COLD}, " w \hat{\imath} T I
\end{aligned}
$$

\subsection{Transshipment model}

In order to calculate the heat and cool utilities as well as the heat exchanged by the entire system, we use a heat cascade diagram, following the conventional approach in pinch analysis (Figure 3). The mathematical formulation of the problem was proposed by Papoulias and Grossmann (1983). The heat cascade diagram can be regarded as a transshipment problem. In this model, hot streams are treated as source nodes, and cold streams as destination nodes. Heat can then be regarded as a commodity that must be transferred from the sources to the destinations through a number intermediate "warehouses" corresponding to the temperature intervals that guarantee feasible heat exchange. When not all of the heat can be allocated to the destinations (cold streams) in a given temperature interval, the excess is cascaded down to lower temperature intervals through the heat residuals.

\section{FIGURE 3}

The equations for the transshipment model can be formulated as follows. We have $w$ temperature intervals that are numbered from the top to bottom. The heat balances of the model are:

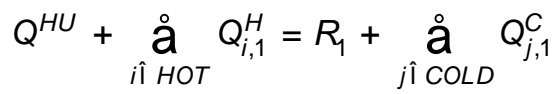

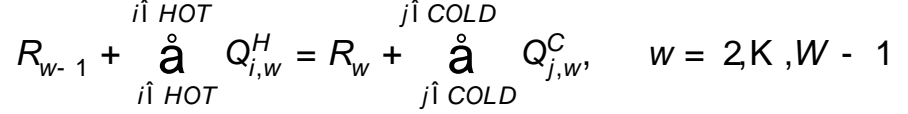

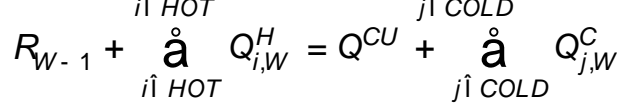

$$
\begin{aligned}
& R_{w}=0
\end{aligned}
$$

This model correctly predicts the minimum utility for variable inlet temperatures, but at a high cost in terms of computational performance. The reasons for this have to do with the large number of combinations of binary variables that lead to infeasible subproblems and a relaxation gap that is too large. These problems can be overcome by first including a preprocessing step to fix a priori some binary variables (this preprocessing is explained in the next section); and by adding a set of logical relationships among the $Y_{k, k^{\prime}}$ Boolean variables, which deal with the 
arrangement of the inlet temperatures, and the $Z$ Boolean variables, which are related to the heat transferred by a stream within a certain temperature interval.

\subsection{Logical relationships relating reordering and heat exchange binary variables}

To make the mathematical formulation as simple as possible, it is convenient to recall that the sets HOT (hot streams), COLD (cold streams), ST (streams = HOT U COLD) and TI (Temperature intervals) are ordered sets. For simplicity, it is also convenient to define the following additional sets:

$$
\begin{aligned}
& P H I_{k, i}=\{\text { Streams in sets } k \hat{\imath} S T, i \hat{\imath} H O T \text { if } k=i\} \\
& P C I_{k, j}=\{\text { Streams in sets } k \hat{\imath} S T, j \hat{\imath} \operatorname{COLD} \text { if } k=n H+j\}
\end{aligned}
$$

\section{Hot Streams}

1. If the inlet temperature of the hot stream $\mathrm{i}\left(i \hat{\mathrm{I}} P H I_{k, i}\right)$ is assigned to position $\mathrm{k}^{\prime}$ then this stream does not exchange heat in any temperature interval above that defined by the position k' (see Figure 4a)

$$
Y_{k k^{\prime}} \triangleright Z_{i, w}^{H 1}(k, i) \hat{\imath} P H I_{k i}, " w i ̂ s T, " k^{\prime} \hat{\imath} S T, " w £ k^{\prime}
$$

2. If the inlet temperature of the hot stream $\mathrm{i}\left(i \hat{\mathrm{I}} \mathrm{PHI} \mathrm{k}_{k, i}\right)$ is assigned to position $\mathrm{k}^{\prime}$ then this stream exchanges heat in the temperature interval starting at that position (counting top to down). The stream either traverses that interval or finishes somewhere inside it (See Figure 4.b)

$$
Y_{k, k^{\prime}} \mathrm{P} Z_{i, w}^{H^{3}} \underline{\underline{U}} Z_{i, w}^{H 4} \quad(k, i) \hat{\imath} P H I_{k, i}, " w \hat{\imath} I T, " k^{\prime} \hat{\imath} S T, w=k^{\prime}+1
$$

3. If the hot stream i ( $\left.i \hat{\imath} P H I_{k, i}\right)$ does not exchange heat in a given interval then the inlet temperature of that stream cannot be assigned to position k', which defines the upper value of the interval (See Figure 4c)

$$
\varnothing Z_{i, w}^{H} \mathrm{P} \varnothing Y_{k, k^{\prime}} \quad(k, i) \hat{I} \quad P H I_{k . i}, " w \hat{I} T I, " k ' \hat{I} S T, w=k^{\prime}+1
$$

4. If the outlet temperature of the hot stream i $\left(i \hat{\imath} P H I_{k, i}\right)$ is inside a temperature interval ' $w$ ' then the inlet temperature of that stream cannot be in any interval below w (See Figure 4d)

$$
Z_{i, w}^{H 4} \mathrm{P} \varnothing Y_{k, k^{\prime}}(k, i) \hat{\imath} P H I_{k, i}, " w \hat{\imath} T I, " k^{\prime} \hat{\imath} S T, k^{\prime 3} w
$$




\section{FIGURE 4}

\section{Cold Streams}

5. If the inlet temperature of the cold stream $j\left(j \hat{\imath} P C l_{k, j}\right)$ is assigned to position $\mathrm{k}^{\prime}$ then this stream does not exchange heat in any temperature interval below that defined by the position $\mathrm{k}^{\prime}$

$$
Y_{k, k^{\prime}} P Z_{j, w}^{C 2}(k, j) \hat{\imath} P C l_{k, j}, k^{\prime} \hat{\imath} S T, " w^{3} k^{\prime}+1
$$

6. If the inlet temperature of the cold stream $\mathrm{j}\left(j \hat{\mathrm{I}} P C l_{k, j}\right)$ is assigned to position $\mathrm{k}^{\prime}$ then this stream exchanges heat in the temperature interval finishing at that position (counting top to down). The stream either traverses that interval or finishes somewhere inside it.

$$
Y_{k, k^{\prime}} \text { P } Z_{j, w}^{C 3} \underline{\underline{u}} Z_{j, w}^{C 4}(k, j) \hat{I} P C l_{k j}, " w \hat{I} I T, " k^{\prime} i ̂ S T, w=k^{\prime}
$$

7. If the cold stream $\mathrm{j}\left(j \hat{\mathrm{I}} \mathrm{PCl}_{k, j}\right.$ ) does not exchange heat in a given interval then the inlet temperature of that stream cannot be assigned to the position k', which defines the lower value of the interval:

$$
\varnothing Z_{j, w}^{C} \triangleright \varnothing_{k, k^{\prime}}(k, j) \hat{\imath} P C l_{k, j}, " w \hat{\imath} T I, " k^{\prime} \hat{\imath} S T, k^{\prime}=w
$$

8. If the outlet temperature of the cold stream ' $j$ ' ( $j \hat{\imath} P C l_{k, j}$ ) is inside a temperature interval ' $w$ ' then the inlet temperature of that stream cannot be in any interval above $w$.

$$
Z_{j, w}^{C 4} \mathrm{P} \quad \varnothing Y_{k, k^{\prime}} \quad(k, j) \hat{\imath} P C l_{k, j}, " w \hat{\imath} T I, " k^{\prime} \hat{\imath} S T, k^{\prime} £ w-1
$$

The scheme of these logical relationships for the cold streams is similar to that of the hot streams shown in Figure 4. However, in the case of cold streams the heat exchange is produced in the opposite direction (from cold to hot temperatures). 


\subsection{Logical relationships involving heat exchange intervals}

1. If a hot/cold stream is below the temperature interval $w$, then it is also below all the intervals above w.

$$
\begin{aligned}
& Z_{i, w}^{H 1} \triangleright Z_{i, w-1}^{H 1} \quad i \text { î HOT; " } w(w>1) \hat{\imath} T I \\
& Z_{j, w}^{C 1} \triangleright Z_{j, w-1}^{C 1} \quad " j \text { î COLD; " } w(w>1) \hat{I} T I
\end{aligned}
$$

2. If a hot/cold stream is above the temperature interval $w$, then it is also above all the intervals below w.

$$
\begin{aligned}
& Z_{i, w}^{H 2} \mathrm{P} Z_{i, w+1}^{H 2} \text { " } i \text { î HOT; " } w\left(w^{1} w\right) \hat{\imath} T I \\
& Z_{j, w}^{C 2} \mathrm{P} Z_{j, w+1}^{C 2} \quad " j \text { î COLD; " } w\left(w^{1} w\right) \hat{l} T I
\end{aligned}
$$

3. If a hot/cold stream finishes the heat exchange in the interval $w$, then that stream does not exchange heat in the temperature intervals below/above $\mathrm{w}$.

$$
\begin{aligned}
& Z_{i, w}^{H 4} \text { ค } Z_{i, w+1}^{H 2} \text { " } i \text { î HOT; " } w\left(w^{1} W\right) \hat{l} T I \\
& Z_{j, w}^{C 4} \circ Z_{j, w-1}^{C 2} \quad " j \text { î COLD; " } w(w>1) \hat{l} T I
\end{aligned}
$$

Note that although equations (53) and (54) only force the variables $\mathrm{Z}^{\mathrm{H} 2}, \mathrm{Z}^{\mathrm{C2}}$ to be true in the interval immediately above/below $w$, the equations (51) and (52) then become active and force these variables to be active in the rest of the intervals above/below the interval $w$.

4. If a hot stream exchanges heat in a temperature interval $w$, then in the following interval (top to bottom) it either continues exchanging heat, or finishes exchanging heat, or does not exchange heat at all.

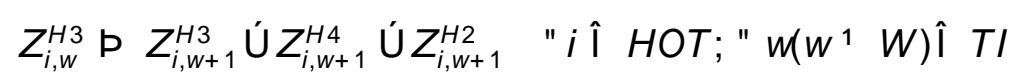

5. If a cold stream exchanges heat in a temperature interval $w$, then in the following interval (bottom to top) it either continues exchanging heat or finishes exchanging heat, or does not exchange heat at all.

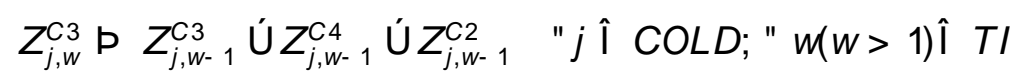




\subsection{Preprocessing}

The objective of preprocessing is to reduce the size of the problem: reducing the number of variables by assigning fixed values to certain binary variables $\left(y_{k, k k}\right)$ and by extension to some $z$ variables; or by limiting the number of intervals that a given stream can be assigned to. A key characteristic of the present model is that the complexity of the resulting model depends on the degree of overlapping in the inlet temperature intervals, for both the hot and cold streams. Two extreme situations can arise: the first occurs when all the inlet temperatures are fixed; in this case all the binary variables can be fixed a priori and the model becomes an LP model (no integer variables): it reduces to the transshipment problem (S.A. Papoulias \& I. E. Grossmann, 1983). The other extreme occurs when all the inlet temperatures overlap; in this case it is not possible to do any a priori assignment. As important as fixing some assignments is restricting the intervals of values to which a given inlet stream temperature can be assigned is just as important.

Consider, for example, Figure 5, which corresponds to test 3 in example 2 (See Table 3). It shows the minimum and maximum values for the inlet temperatures of both hot and cold streams; the streams are arranged by upper bound, and have been drawn accordingly. In this way it is possible verify that stream $\mathrm{H} 1$ can only be assigned to position 1 ; streams $\mathrm{C} 3, \mathrm{C} 4$, and $\mathrm{H} 2$ only to positions 2,3 or 4 ; stream $\mathrm{H} 4$ to positions 5 or 6 ; stream $\mathrm{C} 2$ to positions 5,6 or 7 ; stream $\mathrm{H} 3$ to positions 6 or 7 , and finally, stream $\mathrm{C} 1$ to position 8 .

Note that if two inlet temperatures are equal we obtain a degenerate interval of temperatures (the upper and lower bound temperatures of the interval are the same). Note also that, in Figure 5 , we have drawn the positions for the assignments according to the upper temperatures of the inlet streams. Therefore, positions 5 and 6 appear to overlap but this does not mean that they necessarily have to in the final optimal solutions.

Based on the foregoing analysis, it now becomes straightforward to set some values of the $Z^{H}$ and $Z^{C}$ variables equal to zero - just by inspecting the outlet temperatures of the various streams.

Finally, once some inlet temperatures are constrained to lie in a reduced number of intervals, the upper and lower bounds of temperatures for that interval can be adjusted to obtain a tighter model (i.e. adjusted to the minimum and maximum of the inlet temperatures of the streams that could start in that interval).

\section{FIGURE 5}




\subsection{Final Remarks, extensions and performance of the disjunctive model}

There are several important considerations and extensions of the above model that deserve a more detailed discussion.

The first important point pertains to the model's performance. In other words, when and why could we expect a better performance from this model versus the "pinch location" method? Specifically, the comparison is with the disjunctive implementation by Grossmann et al (1998):

1. The logical relationships in sections 3.4 and 3.5 , as well as the preprocessing stage, can be removed from the model. The optimal solution remains the same, however under these conditions the performance is really bad (e.g. very poor relaxation gap and large CPU times). In that case increasing the number of equations will improve the model's performance.

2. How the model performs is directly related to the degree of overlapping of the interval of possible variation of the inlet temperatures: the lower the extent of overlapping the better the performance of the model (it is important to remark that the overlap is only in the variation of inlet temperatures and not between the inlet and outlet temperatures). Test problems 3 and 4 (see the Examples section) show that the relaxation gap drastically decreases with overlapping degree. The relaxation gap in these examples is much better than that which results from using the disjunctive implementation of the pinch location method by Grossmann et al. An extreme situation occurs when there is no overlapping at all; in that case all the binary variables and most of the variables are fixed and the model is an LP or NLP.

3. Related to the previous point, it is worth noting that although the difference between inlet and outlet temperatures of a stream can be large, in industrial practice the bounds for the inlet temperature are subject to physical and practical constraints that in most situations prevent large intervals. Therefore, a small degree of overlapping is not uncommon.

4. The large number of constraints (compared with the pinch location method) is only a minor problem, for two main reasons: 1) All the constraints are linear, and modern solvers can deal very efficiently with very large sets of linear equations; 2) The preprocessing step in any modern solver drastically reduces the number of equations and variables that the model must effectively solve. For example, in test problem 3 -see the Examples section - the problem size is reduced from 5375 equations and 2125 variables to 675 equations and 283 variables: a reduction in size of more than $85 \%$. The examples show that the effective number of equations and variables in both the pinch location and proposed model are on the same order of magnitude. 
It is also of interest to show how the model can be extended to take into account some situations that were not specifically addressed before: isothermal streams, multiple utilities or forbidden matches.

Isothermal streams. The easiest way to deal with these streams is to assume a small fictitious temperature difference between the inlet and outlet temperatures (say 1, 0.1, $0.01^{\circ} \mathrm{C}$ ) and to calculate the correct heat flow rate. Alternatively, it is possible to define a temperature interval of $\Delta T=0{ }^{\circ} \mathrm{C}$, in which only the isothermal stream can exchange heat. This requires changing the equations for the heat exchange of the affected streams.

Multiple utilities. If the utility is an isothermal stream (e.g. HP, MP, LP saturated steam), it is possible to introduce the utility by using either of the two approaches for isothermal streams mentioned in the paragraph immediately above; however, the objective function must now take into account the cost of the utility. Note that the variable will be the total heat exchanged by the utility, or the heat flow rate (mass flow rate if the heat capacity is constant). In any case, the model continues to be linear. If the utility is a nonisothermal stream (e.g. refrigeration water) with fixed inlet and outlet temperatures, it can be introduced as any other stream, but in this case the temperatures are fixed and the heat flow rate is variable. Again, linearity is retained.

Forbidden matches. In the model presented, it is implicitly assumed that all the hot streams can exchange heat with all the cold streams. The implementation of forbidden matches is straightforward simply by changing the domain of equations involving heat exchange (i.e. by defining a set of permitted matches and defining the equations over this set).

Both the "pinch location method" and the proposed model assume that the pinch point can be located at any of the inlet temperatures of the process streams. This is always true only if the heat flow rate in any stream is assumed to be constant, or vice versa: the inlet and outlet temperatures are constant and the heat flow rate can change. However, if both the temperatures and flows can vary at the same time, we cannot be sure that the pinch point will be located at an inlet temperature (e.g. when the heat capacity depends on the temperature). A typical approach to overcome this problem is to use a piecewise linear approximation, but if there is a complex relationship between the heat flow rate and temperatures it is not always possible to use such an approach; consequently, both models must be used with caution. 


\section{EXAMPLES AND RESULTS}

In this section, a number of different examples are presented. They include problems involving: fixed and variable stream temperatures (MILP); heat integration of distillation columns, in which the temperature of the streams depends on the operating conditions of the columns (MINLP); and flowsheet process optimization and heat integration using the hybrid simulation optimization approach, in which the process is solved by a commercial process simulator (ASPEN-HYSYS), and the heat integration model is in equation form.

All calculations were performed on GAMS (McCarl, 2010) and MATLAB-TOMLAB (Holmström, 1999), while simulations were performed on ASPEN-HYSYS.

\subsection{Process with fixed streams conditions (MILP)}

First, in order to validate the model, we solve the easiest possible example, in which temperatures (both inlet and outlet) and heat flow rates are known and constant (See Table 1). The objective is to determine the minimum utilities cost ( $\min \mathrm{C}_{\mathrm{H}} \mathrm{Q}_{\mathrm{Hot}}+\mathrm{C}_{\mathrm{C}} \mathrm{Q}_{\text {cold }}$ ). From a mathematical point of view, this problem involves binary and continuous variables, and all the equations used in the model are linear; so this problem must be solved as a Mixed Integer Linear Problem (MILP), which was done on GAMS-CPLEX. Finally, to test the behavior of the model, we compare its results with those obtained by the pinch location method according to the disjunctive implementation proposed by Grossmann et al (1998).

Under these conditions the temperature intervals are fixed and can be calculated a priori, and the problem becomes one of "classical" heat integration, which can be solved either by hand (e.g. problem table by Linnhoff (Linnhoff \& Engineers, 1982; Linnhoff \& Flower, 1978a)) or by using the transshipment problem proposed by Papoulias \& Grossmann (1983). The proposed model can capture this fact in the preprocessing stage, and then all binary variables will be fixed. Therefore, Table 2 contains results which have been obtained with the preprocessing stage deactivated.

\section{Table 1}

Table 2 shows, for both methods described above, the solution to this example and some parameters relevant to the problem.

\section{Table 2}

As expected, the computational results show that the number of variables, in particular binary variables, is considerably larger in the proposed model versus the pinch location method. However, as mentioned earlier, both models exhibit comparable computational performance (See Table 2). 
Finally, as a check on the proposed model, we find that both models obtain exactly the same solution (\$6700).

\subsection{Process with variable stream conditions (MILP)}

The following examples (test problems 2 and 3) illustrate the case in which there is a range of inlet and outlet temperatures for hot and cold streams - under the assumption that this variation does not have an impact on process performance. In other words, we have an extra degree of freedom of variable temperatures for the heat integration that does affect the rest of the process. Whereas this is a valid approximation in many systems, our main interest here focuses on testing the affected part of the model. All the problems were solved for a heat recovery temperature (HRAT) of $10 \mathrm{~K}$. For comparison purposes, the test problems were also solved by the pinch location method.

The main objective of these examples is to show how the overlapping degree in the possible range of inlet temperatures affects the model's performance. As in the previous case, the objective function minimizes the utility cost $\left(\min C^{H U} Q^{H U}+C^{C U} Q^{C U}\right)$. In all cases the heat flow rates are assumed to be constant (See Table 3).

In test problem 2 the bounds of almost all the inlet temperatures overlap and therefore the preprocessing stage has a low impact on the model's performance. In both the 'pinch location method' and the proposed approach the relaxation gap is really bad (objective function equal to zero).

\section{Table 3}

However, in test problem 3, the overlapping of the bounds of inlet temperatures is moderate, see Figure 5. The optimal solution is $\$ 4060$ but the relaxation gap of the proposed model is much better than that obtained by the pinch location method (3124 vs 620). Results and relevant parameters for the test problems are shown in Tables 4 and 5, respectively.

It is worth noticing the important reduction in the number of equations and variables in the preprocessing stage: the problem size is reduced from 5375 equations and 2125 variables to 675 equations and 283 variables. This represents a reduction in size of more than $85 \%$.

\section{Table 4-5}

Any modification to the operating conditions of a process that is running optimally with respect to a given objective function, introduces a penalty into that function. Test problem 4 tries to capture in a simple way the tradeoff between improvements due to energy savings and deviations from the optimal point of the process when heat integration is not considered. To this end, we use a set of values for the inlet and outlet temperatures that corresponds to 
temperatures at the optimal operating conditions when heat integration is not taken into account. The objective function then consists of two terms; the first one pertains to the cost of utilities, and the second one penalizes the deviation of temperature from a given set value:

$$
\min : \text { Cost of utilities }+\underset{k \hat{I} S T}{\stackrel{\bigcirc}{(T S}}\left(T_{k}^{\text {in }}-T M_{k}^{\text {in }}\right)^{2}+\left(T_{k}^{\text {out }}-T M_{k}^{\text {out }}\right)^{2}
$$

where the $T M$ are the optimal temperatures of the non-heat integrated process (here we have taken the central value between the upper and lower bounds of the inlet and outlet temperatures).

Again, the overlapping degree in this example is moderate; preprocessing and logical relationships reduce the relaxation gap as compared to the pinch location method (1904 vs 767). Data, results and other relevant parameters for this example are shown in Tables 3,4 and 5 , respectively.

\subsection{Heat integration of distillation columns (MINLP)}

This example corresponds to the general case in which the heat integration cannot be isolated from the rest of the process, and therefore the temperatures of the streams depend on the remaining operating conditions for the process. Here, we studied the heat integration of a distillation column sequence: in particular, the separation of a mixture of 4 components using sharp distillation (Figure 6). In this case, the temperature of hot and cold streams depends on the pressure inside each column and on the purity specifications.

\section{Figure 6}

We assume that design of the columns is not the main objective, and that the investment cost is not significantly changed with respect to optimal operation without heat integration. In that way we can focus on the energy integration, and at the same time simplify the problem. The sharp distillation has as main feature that the components of the mixture are essentially separated completely between distillate and bottoms. In a sharp distillation, we know in advance what the composition of the products in each column is. Using this property, we study the temperature range of the various distillates and bottoms expected in each column as a function of the column pressure (pressure range: $1-3 \mathrm{~atm}$ ), by means of a chemical process simulator (ASPEN-HYSYS). Then, the temperature of each stream is fitted to a quadratic polynomial in terms of column pressure, which is the expression we finally used in the model. At the same time, the heat flow rate $\left(F C_{P}\right)$ is not constant and depends on the column pressure; in this case a linear relationship is assumed. The resulting problem is a MINLP problem, solved on GAMSDICOPT. 
As an example, we consider the separation of $200 \mathrm{kmol} / \mathrm{h}$ of an equimolar mixture of benzene, toluene, $p$-xylene and $\alpha$-methyl-styrene (molar fraction of 0.25 benzene, 0.25 toluene, $0.25 p$ xylene and $0.25 \alpha$-methyl-styrene). We assume that all the benzene and toluene is obtained in the distillate of column 1 , while all the p-xylene and $\alpha$-methyl-styrene is obtained in the bottoms of column 1. The benzene and toluene are obtained in the distillate and bottoms of column 2 , respectively. Finally, the $p$-xylene and $\alpha$-methyl-styrene are obtained in the distillate and bottoms of column 3, respectively. The flows and temperatures of the hot and cold streams are shown in Table 6.

\section{Table 6}

Table 7 collects the solution to this example and some relevant information regarding the computational results.

\section{Table 7}

The CPU times taken by both models are on the same order of magnitude. This implies that both models are of comparable complexity and perform in a similar way. Moreover, the results that have been obtained are different. The main reason for this is that the problem is nonlinear and non-convex, and therefore a global optimal solution cannot be guaranteed. However, the optimal solutions that have been obtained are quite close. From the point of view of relaxation, in this case both models perform poorly (objective function value equal to zero in both cases).

\subsection{Hybrid simulation-optimization process (MINLP)}

Finally, we considered a problem in which mathematical programming with the explicit equations is combined with the robust models that are available in commercial chemical process simulators. The process is implemented in the simulator and the resulting system is interfaced with MATLAB ${ }^{\circledR}$ via ActiveX controls; it is optimized using MATLAB-TOMLAB $®$ and a proprietary implementation of the outer approximation algorithm (Duran \& Grossmann, 1986a; Kocis \& Grossmann, 1987; Viswanathan \& Grossmann, 1990) that has been adapted to MATLAB. The problem is a mixed-integer nonlinear programming (MINLP) problem in which some of the equations appear in an implicit form (equations in the process simulator), while the others appear explicitly.

Heat integration of the problem proposed by Seider el at. (1999) was selected as case study of a problem of this type (see Figure 7). A natural gas stream is processed at $5000 \mathrm{kmol} / \mathrm{h}, 20^{\circ} \mathrm{C}$, $10 \mathrm{~atm}$, and with the composition shown in Table 8. The gaseous product is required to be at 20 atm, with at least $4900 \mathrm{kmol} / \mathrm{h}$ of $\mathrm{nC} 4$ and lighter species with a combined mole percentage of at least $99.5 \%$. 


\section{Table 8}

\section{FIGURE 7}

In this example the process simulator, HYSYS ${ }^{\circledR}$, performs the calculation at the flowsheet level, including all mass and energy balances and all estimations of properties. As in the previous example, to avoid the behavior of the process interfering with the performance of the energy integration model, we assume that the cost of the process is not substantially affected; as a result, it is not taken into account. Therefore, we only perform heat integration of the process, and because of this, the objective of this problem is to minimize the heat supplied by the hot and cold utilities. The streams affected by the heat integration were all inlet and outlet streams of the heat exchangers. The temperature bounds for all streams, the main constraints, the optimal solution and some information on the procedure used to obtain the solution are shown in Table 9.

\section{Table 9}

The optimal solution satisfies all the proposed constraints. Furthermore, the heat integration of the system eliminates the need for hot utilities; only cold utilities are needed to satisfy the requirements of the process. The CPU time is not displayed in Table 9 because the simulator uses up most of the time to converge the system, and therefore this parameter is not representative of the model.

In this example, there is little overlapping among the inlet temperatures of the process streams. Both models reach the optimal solution in the relaxed MINLP problem.

This example shows that the proposed approach is robust and flexible and can be implemented by adding some equations to any existing model with minor modifications to the original model.

\section{CONCLUSIONS}

An alternative model has been proposed for the simultaneous optimization and energy integration of non-isothermal systems. Even though this results in a larger problem than is typically encountered in other models, a preprocessing stage for the data and the inclusion of some logical relationships substantially reduces the size of the initial problem. In fact, this alternative model competes successfully with the disjunctive implementation of the pinch location method by Grossmann et al (Ignacio E. Grossmann et al., 1998) from the point of view of CPU time and relaxation gap. 
The performance of the model is directly related to the overlapping degree of the bounds of the inlet temperatures for the process streams. With moderate to small overlapping the proposed model improves the relaxation gap with respect to the disjunctive implementation of the pinch location method.

In addition, the alternative model manages to maintain the temperature interval concept in contrast to existing models. This feature is interesting to some engineers and researchers that are familiar with the classical concept of temperature interval in heat integration. Finally, the proposed model eliminates the numerical difficulties associated with the use of the max function or smoothing approximation function, and therefore provides a robust alternative model.

\section{ACKNOWLEDGMENTS}

The authors gratefully acknowledge financial support from the Spanish "Ministerio de Ciencia e Innovación" under project CTQ2012-37039-C02-02. 


\section{Bibliography}

Ahmad, S., Linnhoff, B., \& Smith, R. (1990). Cost optimum heat exchanger networks-2. targets and design for detailed capital cost models. Computers \&amp; Chemical Engineering, 14, 751-767.

Biegler, L. T., Grossmann, I. E., \& Westerberg, A. W. (1997). Systematic methods of chemical process design: Prentice Hall PTR.

Caballero, J. A., \& Grossmann, I. E. (1999). Aggregated models for integrated distillation systems. Industrial and Engineering Chemistry Research, 38, 2330-2344.

Caballero, J. A., \& Grossmann, I. E. (2006). Structural considerations and modeling in the synthesis of heat-integrated-thermally coupled distillation sequences. Industrial \& Engineering Chemistry Research, 45, 8454-8474.

Cerda, J., \& Westerburg, A. W. (1983). Synthesizing heat exchanger networks having restricted stream/stream matches using transportation problem formulations. Chemical Engineering Science, 38, 1723-1740.

Ciric, A. R., \& Floudas, C. A. (1991). Heat exchanger network synthesis without decomposition. Computers \&amp; Chemical Engineering, 15, 385-396.

Douglas, J. M. (1985). A hierarchical decision procedure for process synthesis. Aiche Journal, 31, 353-362.

Douglas, J. M. (1988). Conceptual design of chemical processes: McGraw-Hill.

Duran, M. A., \& Grossmann, I. E. (1986a). An Outer-Approximation Algorithm For A Class Of Mixed-Integer Nonlinear Programs. Mathematical Programming, 36, 307-339.

Duran, M. A., \& Grossmann, I. E. (1986b). Simultaneous optimization and heat integration of chemical processes. AIChE Journal, 32, 123-138.

Duran, M. A., \& Grossmann, I. E. (1986c). Simultaneous optimization and heat integration of chemical processes. AlChE Journal, 32, 123.

Floudas, C. A., \& Ciric, A. R. (1989). Strategies for overcoming uncertainties in heat exchanger network synthesis. Computers \&amp; Chemical Engineering, 13, 1133-1152.

Floudas, C. A., Ciric, A. R., \& Grossmann, I. E. (1986). Automatic synthesis of optimum heat exchanger network configurations. AlChE Journal, 32, 276-290.

Floudas, C. A., \& Paules, G. E. (1988). A mixed-integer nonlinear programming formulation for the synthesis of heat-integrated distillation sequences. Computers \&amp; Chemical Engineering, 12, 531-546.

Furman, K. C., \& Sahinidis, N. V. (2002). A Critical Review and Annotated Bibliography for Heat Exchanger Network Synthesis in the 20th Century. Industrial \& Engineering Chemistry Research, 41, 2335-2370.

Grossmann, I. E., Yeomans, H., \& Kravanja, Z. (1998). A rigorous disjunctive optimization model for simultaneous flowsheet optimization and heat integration. Computers \& Chemical Engineering, 22, S157-S164.

Grossmann, I. E., Yeomans, H., \& Kravanja, Z. (1998). A rigorous disjunctive optimization model for simultaneous flowsheet optimization and heat integration. Computers \&amp; Chemical Engineering, 22, Supplement 1, S157-S164.

Holmström, K. (1999). The Tomlab Optimization Environment in Matlab. Adv. Model Optim., 1, 47-69.

Kocis, G. R., \& Grossmann, I. E. (1987). Relaxation Strategy For The Structural Optimization Of Process Flow Sheets. Industrial \& Engineering Chemistry Research, 26, 1869-1880.

Linnhoff, B., \& Ahmad, S. (1990). Cost optimum heat exchanger networks-1. Minimum energy and capital using simple models for capital cost. Computers \&amp; Chemical Engineering, 14, 729-750.

Linnhoff, B., \& Engineers, I. o. C. (1982). User guide on process integration for the efficient use of energy: Pergamon Press. 
Linnhoff, B., \& Flower, J. R. (1978a). Synthesis of heat exchanger networks: I. Systematic generation of energy optimal networks. AlChE Journal, 24, 633-642.

Linnhoff, B., \& Flower, J. R. (1978b). Synthesis of heat exchanger networks: II. Evolutionary generation of networks with various criteria of optimality. AIChE Journal, 24, 642-654.

Linnhoff, B., \& Hindmarsh, E. (1983). The pinch design method for heat exchanger networks. Chemical Engineering Science, 38, 745-763.

McCarl, B. A. (2010). McCarl Expanded GAMS User Guide Version 23.3: Texas A\&M University.

Morar, M., \& Agachi, P. S. (2010a). Review: Important contributions in development and improvement of the heat integration techniques. Computers \& Chemical Engineering, 34, 1171-1179.

Morar, M., \& Agachi, P. S. (2010b). Review: Important contributions in development and improvement of the heat integration techniques. Computers \&amp; Chemical Engineering, 34, 1171-1179.

Papoulias, S. A., \& Grossmann, I. E. (1983). A structural optimization approach in process synthesis-II: Heat recovery networks. Computers \&amp; Chemical Engineering, 7, 707-721.

Papoulias, S. A., \& Grossmann, I. E. (1983). A structural optimization approach in process synthesis. Part II: Heat recovery networks. Computers \& Chemical Engineering, 707.

Raman, R., \& Grossmann, I. E. (1993). Symbolic integration of logic in mixed-integer linear programming techniques for process synthesis. Computers \&amp; Chemical Engineering, 17, 909-927.

Seider, W. D., Seader, J. D., \& Lewin, D. R. (1999). Process design principles: synthesis, analysis, and evaluation: Wiley.

Smith, R. (2005). Chemical process design and integration: Wiley.

Smith, R., \& Linnhoff, B. (1988). The Design Of Separators In The Context Of Overall Processes. Chemical Engineering Research \& Design, 66, 195-228.

Viswanathan, J., \& Grossmann, I. E. (1990). A combined penalty function and outerapproximation method for MINLP optimization. Computers \&amp; Chemical Engineering, 14, 769-782.

Yee, T. F., \& Grossmann, I. E. (1990). Simultaneous optimization models for heat integrationII. Heat exchanger network synthesis. Computers \&amp; Chemical Engineering, 14, 1165-1184.

Yee, T. F., Grossmann, I. E., \& Kravanja, Z. (1990a). Simultaneous optimization models for heat integration-I. Area and energy targeting and modeling of multi-stream exchangers. Computers \&amp; Chemical Engineering, 14, 1151-1164.

Yee, T. F., Grossmann, I. E., \& Kravanja, Z. (1990b). Simultaneous optimization models for heat integration-III. Process and heat exchanger network optimization. Computers \&amp; Chemical Engineering, 14, 1185-1200. 


\section{NOTATION}

\section{Continuous Variables}

$T_{H i}^{*, i n}: \quad$ Inlet temperature hot streams

$T_{C i}^{* i n}: \quad$ Inlet temperature cold streams

$T_{H i}^{i n}: \quad$ Modified inlet temperature hot streams

$T_{C i}^{\text {in }}: \quad$ Modified inlet temperature cold streams

$T_{k}^{i n}: \quad$ Auxiliary temperature

$T_{k^{\prime}}^{\text {ord }}$ : Ordered temperature

$T_{w}^{U P} \quad$ Upper temperature in each interval

$T_{w}^{L O} \quad$ Lower Temperature in each interval

$T^{\max }$ : Maximum temperature in the system

$T^{\mathrm{min}}$ : Minimum temperature in the system

$F C P_{i}^{H}: \quad$ Heat Capacity of hot stream (kW/C)

$F C P_{j}^{C}$ : Heat Capacity of cold stream (kW/C)

$Q_{i, w}^{H}: \quad$ Heat exchanged by a hot stream in an interval

$Q_{j, w}^{C}$ : Heat exchanged by a cold stream in an interval

$R_{w}$ : Heat residual in each interval

$Q^{H U}:$ Heat provided by hot utilities

$Q^{C U}:$ Heat removed by cold utilities 


\section{Binary variables}

$y_{k, k^{\prime}}: \quad 1$ if the inlet temperature of stream $\mathrm{k}$ is located at position $\mathrm{k}^{\prime}$ in the sorted list of inlet temperatures, 0 otherwise

$z_{j, w}^{C}: \quad 1$ if the cold stream $\mathrm{j}$ interchanges heat in the interval $w, 0$ otherwise

$z_{j, w}^{C 1}: \quad 1$ if the outlet temperature of the cold stream $\mathrm{j}$ is below the temperature interval $\mathrm{w}$, 0 otherwise

$z_{j, w}^{C 2}: \quad 1$ if the inlet temperature of the cold stream $\mathrm{j}$ is above the temperature interval $\mathrm{w}$, 0 otherwise

$z_{j, w}^{C 3}: \quad 1$ if the cold stream $\mathrm{j}$ traverses the temperature interval $w, 0$ otherwise

$z_{j, w}^{C 4}: \quad 1$ if the outlet temperature of the cold stream $\mathrm{j}$ is inside the temperature interval $\mathrm{w}$, 0 otherwise

$z_{i, w}^{H}: \quad 1$ if the hot stream i exchanges heat in the temperature interval w, 0 otherwise

$z_{i, w}^{H 1}: \quad 1$ if the inlet temperature of the hot stream $\mathrm{i}$ is below the temperature of interval $\mathrm{w}$, 0 otherwise

$z_{i, w}^{H 2}: \quad 1$ if the outlet temperature of the hot stream $\mathrm{i}$ is above the temperature interval $\mathrm{w}$, 0 otherwise

$z_{i, w}^{H 3}: \quad 1$ if the hot stream i traverses the temperature interval $w, 0$ otherwise

$z_{i, w}^{H 4}: \quad 1$ if the outlet temperature of the hot stream $\mathrm{i}$ is inside the temperature interval $\mathrm{w}$, 0 otherwise 


\section{Figure Captions}

Figure 1. Illustration of ordered temperatures and intervals

Figure 2. All the relative positions of a stream in relation to a given temperature interval

Figure $3 . \quad$ Heat cascade diagram

Figure $4 . \quad$ Logical Relationships for hot streams

Figure 5. Minimum and maximum values for the inlet temperatures of hot and cold streams

Figure 6. Sharp distillation for separation of a 4-component mixture

Figure 7. Process flow diagram for the processing of the natural gas 
Table Captions

Table 1 Test Problem 1 (Fixed Temperatures)

Table 2 Results Test Problem 1 (Fixed Temperatures)

Table 3 Test Problems 2 - 4 (Variable Temperatures)

Table 4 Results Test Problems 2-4 (Variable Temperatures)

Table 5 Parameters solution Test Problems 2-4

Table 6 Flows and temperatures of Problem Columns

Table $7 \quad$ Solution of Problem Columns

Table 8 Molar Flow Rate of the Feed $(\mathrm{kmol} / \mathrm{h})$

Table 9 Bounds, constraints and solution of the natural gas problem 


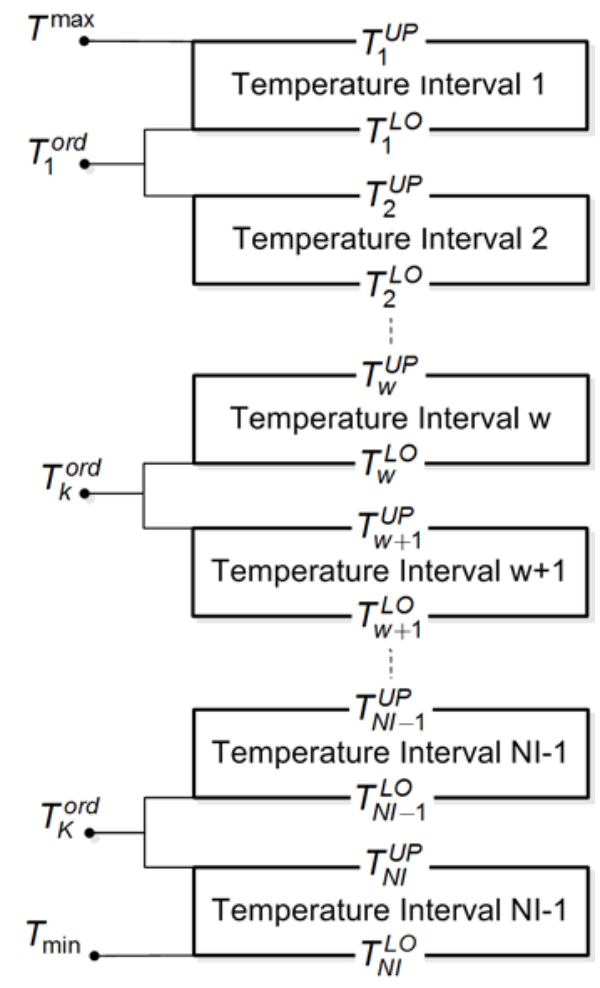

Figure 1. 


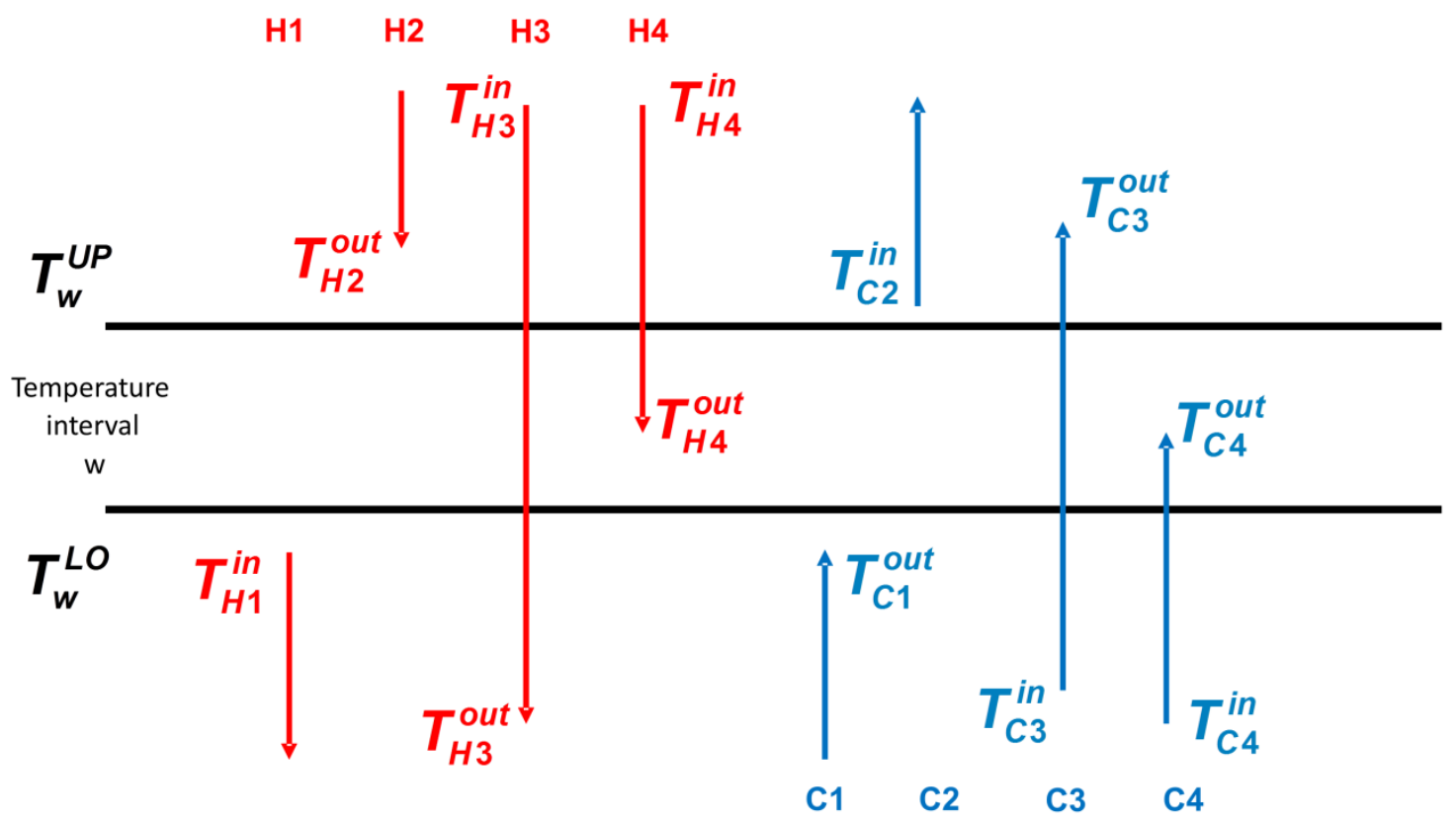

Figure 2 


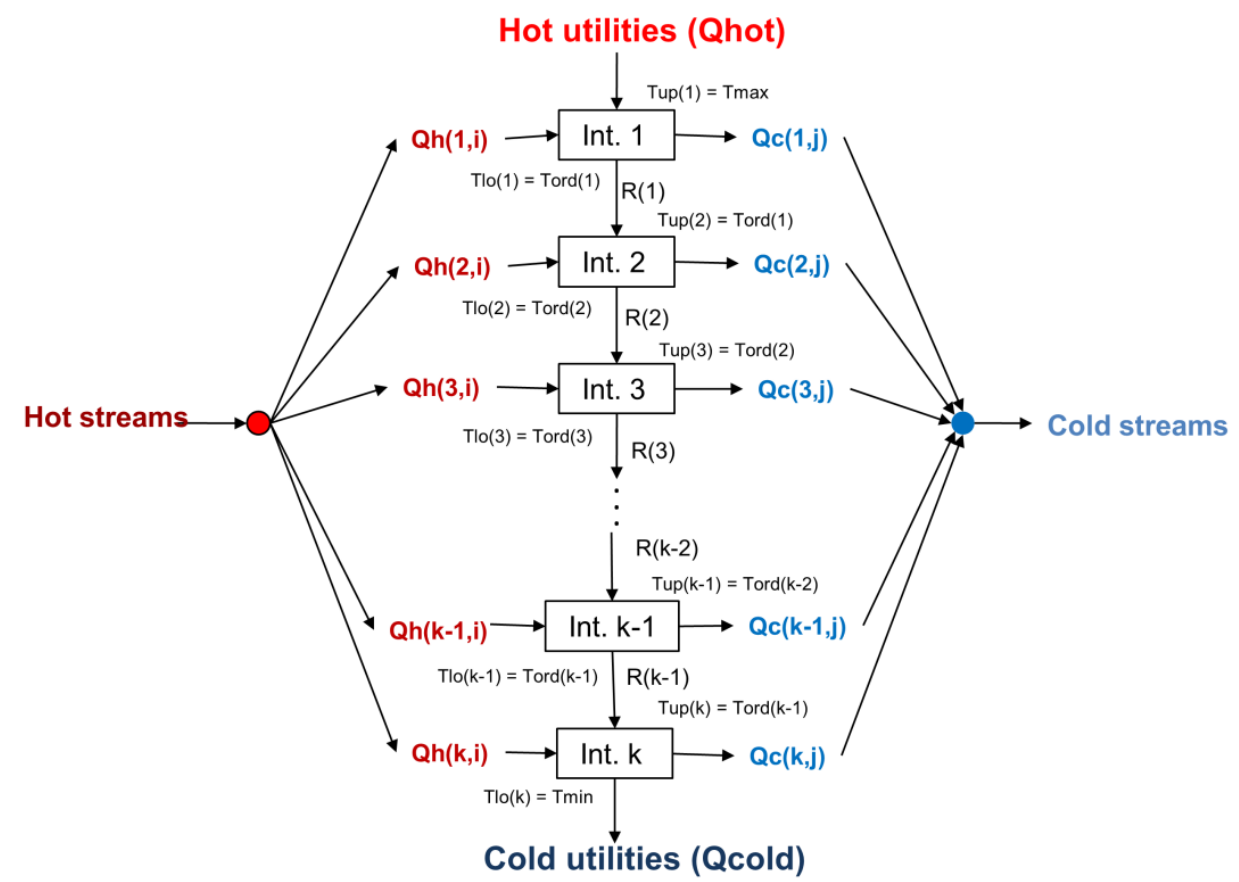

Figure 3 


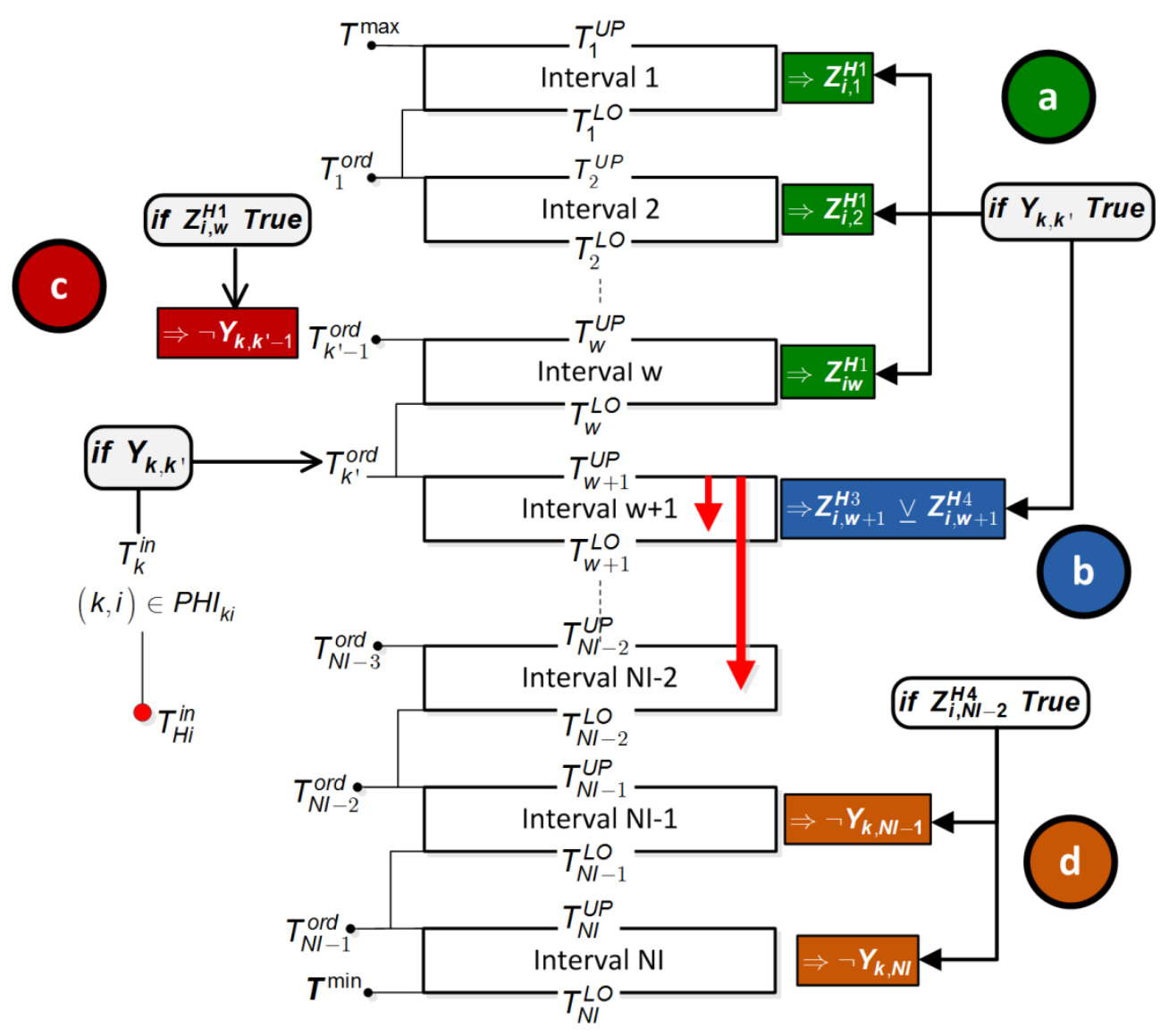

Figure 4 


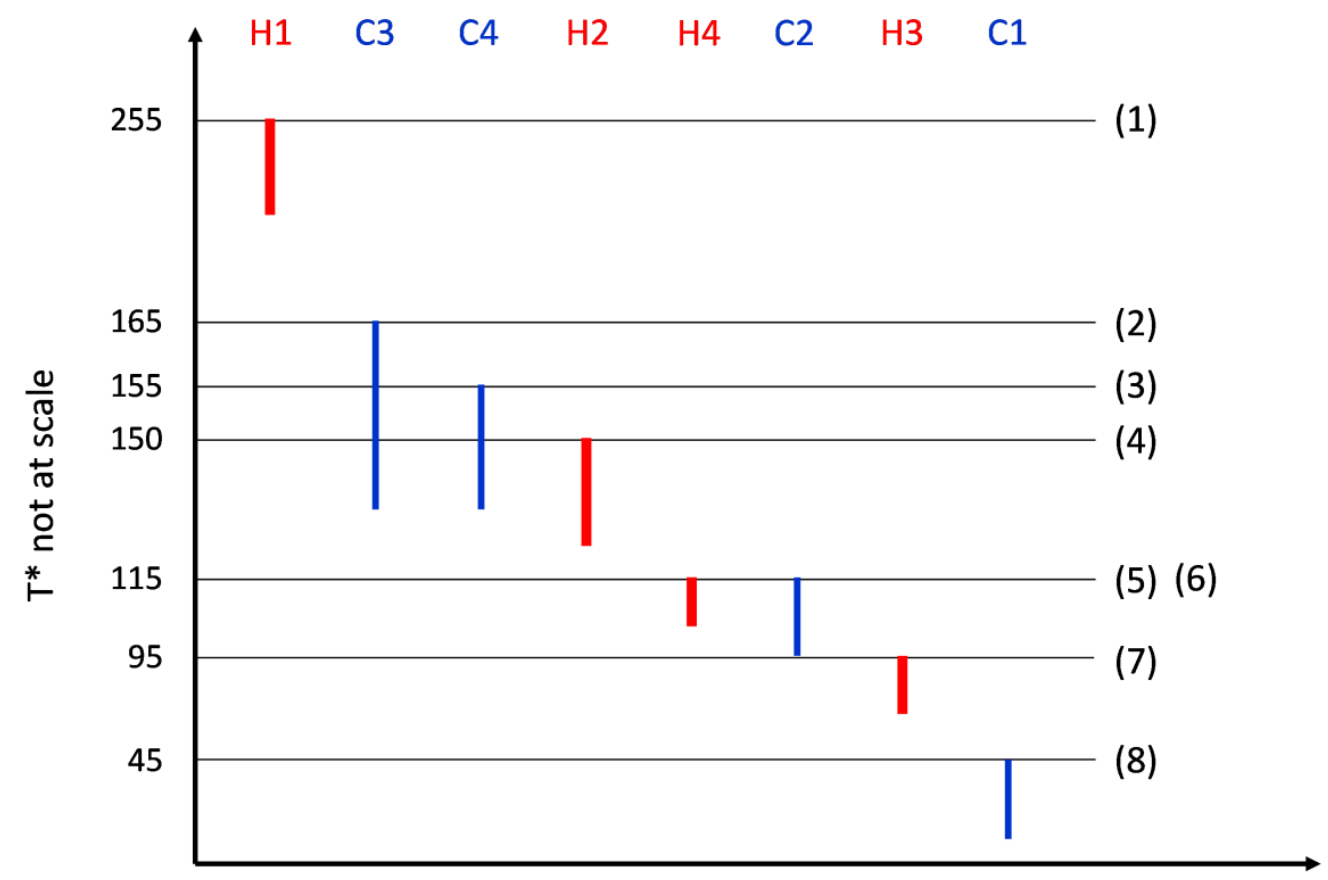

Figure 5 


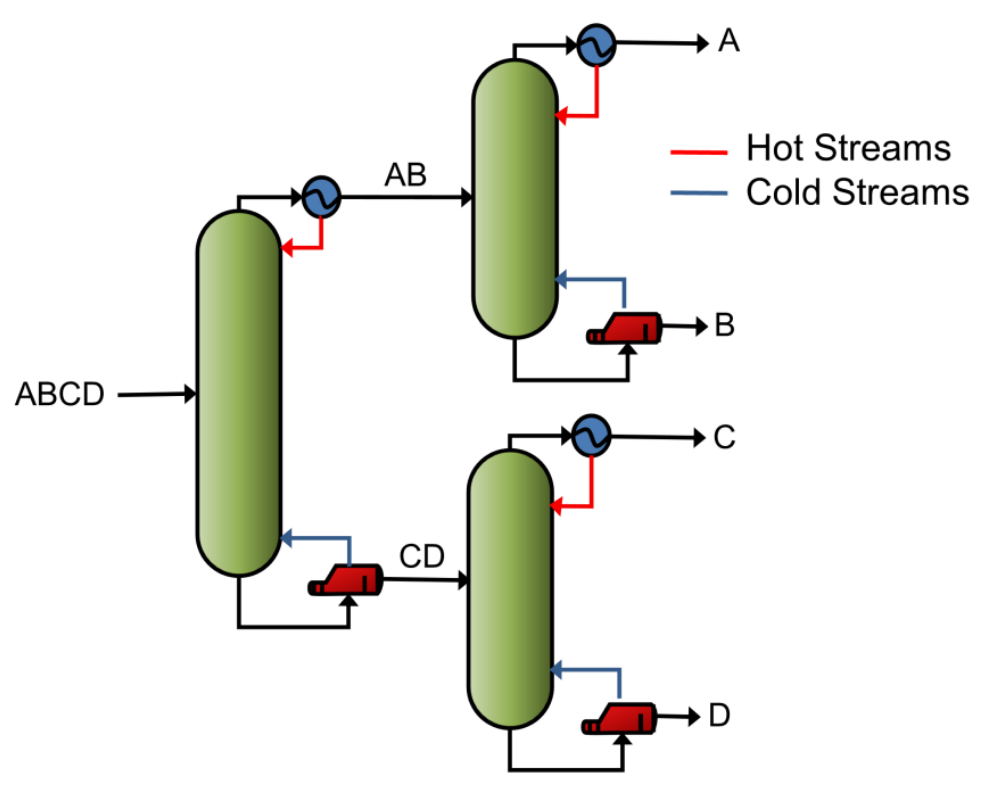

Figure 6 


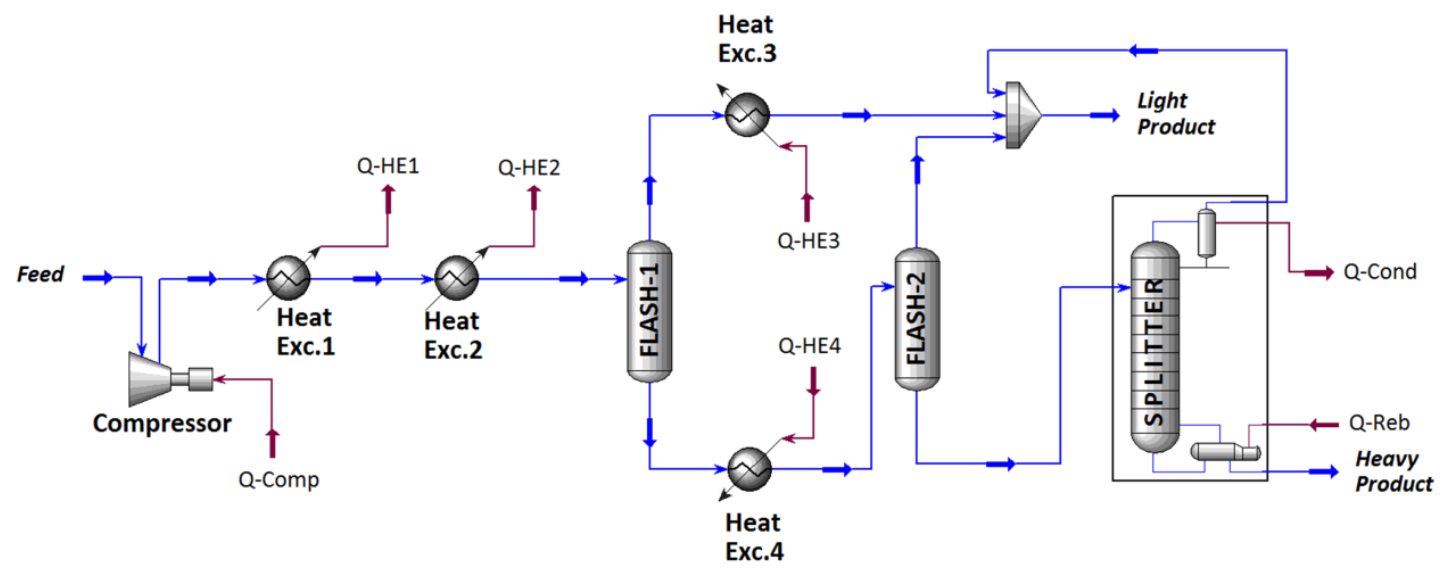

Figure 7 
Table 1

\begin{tabular}{cccc|ccrr}
\hline $\begin{array}{c}\text { Hot } \\
\text { Stream }\end{array}$ & $\begin{array}{c}\text { FCp } \\
\left(\mathbf{k W} /{ }^{\circ} \mathbf{C}\right)\end{array}$ & $\begin{array}{c}\text { Inlet T } \\
\left({ }^{\circ} \mathbf{C}\right)\end{array}$ & $\begin{array}{c}\text { Outlet T } \\
\left({ }^{\circ} \mathbf{C}\right)\end{array}$ & $\begin{array}{c}\text { Cold } \\
\text { Stream }\end{array}$ & $\begin{array}{c}\text { FCp } \\
\left(\mathbf{k W} /{ }^{\circ} \mathbf{C}\right)\end{array}$ & $\begin{array}{c}\text { Inlet T } \\
\left({ }^{\circ} \mathbf{C}\right)\end{array}$ & $\begin{array}{c}\text { Outlet T } \\
\left({ }^{\circ} \mathbf{C}\right)\end{array}$ \\
\hline H1 & 1.00 & 280 & 100 & $\mathrm{C} 1$ & 0.50 & 30 & 200 \\
H2 & 3.00 & 200 & 80 & $\mathrm{C} 2$ & 1.50 & 60 & 90 \\
H3 & 1.00 & 220 & 150 & $\mathrm{C} 3$ & 2.00 & 70 & 170 \\
H4 & 2.00 & 210 & 90 & $\mathrm{C} 4$ & 3.00 & 110 & 230 \\
H5 & 1.00 & 250 & 180 & $\mathrm{C} 5$ & 1.50 & 90 & 140 \\
H6 & 2.00 & 270 & 120 & $\mathrm{C} 6$ & 4.00 & 120 & 250 \\
\hline
\end{tabular}

Price of Steam: $80 \$ \mathbf{~} \cdot \mathrm{kg} / \mathrm{kW}$

Price of Cooling Water: $20 \$ \cdot \mathrm{kg} / \mathrm{kW}$

Table 2

\begin{tabular}{lcc} 
& Results Test Problem 1 & \\
Non-Isothermal & Grossmann et al (G.Y.K) & Present work \\
\hline № Equations & 1622 & 6059 \\
№ Variables & 614 & 1169 \\
№ Binary Variables & 432 & 900 \\
CPU time (sec) & 0.271 & 0.353 \\
Iterations & 0 & 0 \\
\hline Heating Req. (kW/kg) & 80.00 & 80.00 \\
Cooling Req. (kW/kg) & 15.00 & 15.00 \\
Optimal Solution (\$) & 6700.00 & 6700.00
\end{tabular}

* Pentium Dual-Core E5300 2.60GHz, using CPLEX 12.4.0.0for MILP 
Table 3

\begin{tabular}{cccc|cccc}
\hline $\begin{array}{c}\text { Hot } \\
\text { Stream }\end{array}$ & $\begin{array}{c}\mathbf{F C p} \\
\left(\mathbf{k W} /{ }^{\circ} \mathbf{C}\right)\end{array}$ & $\begin{array}{c}\text { Interval } \\
\text { Inlet T }\left({ }^{\circ} \mathbf{C}\right)\end{array}$ & $\begin{array}{c}\text { Interval } \\
\text { Outlet } \mathbf{T}\left({ }^{\circ} \mathbf{C}\right)\end{array}$ & $\begin{array}{c}\text { Cold } \\
\text { Stream }\end{array}$ & $\begin{array}{c}\mathbf{F C p} \\
\left(\mathbf{k W} /{ }^{\circ} \mathbf{C}\right)\end{array}$ & $\begin{array}{c}\text { Interval } \\
\text { Inlet T }\left({ }^{\circ} \mathbf{C}\right)\end{array}$ & $\begin{array}{c}\text { Interval } \\
\text { Outlet T }\left({ }^{\circ} \mathbf{C}\right)\end{array}$ \\
\hline H1 & 0.15 & $180-260$ & $30-50$ & $\mathrm{C} 1$ & 0.20 & $15-135$ & $170-190$ \\
H2 & 0.50 & $120-220$ & $75-95$ & $\mathrm{C} 2$ & 0.30 & $110-190$ & $225-235$ \\
H3 & 0.10 & $110-155$ & $90-100$ & $\mathrm{C} 3$ & 0.15 & $70-130$ & $140-150$ \\
\hline
\end{tabular}

Price of Steam: $80 \$ \cdot k g / k W$

Price of Cooling Water: $20 \$ \cdot \mathrm{kg} / \mathrm{kW}$

\begin{tabular}{cccc|cccc}
\hline $\begin{array}{c}\text { Hot } \\
\text { Stream }\end{array}$ & $\begin{array}{c}\mathrm{FCp} \\
\left(\mathbf{k W} /{ }^{\circ} \mathbf{C}\right)\end{array}$ & $\begin{array}{c}\text { Interval } \\
\text { Inlet T }\left({ }^{\circ} \mathbf{C}\right)\end{array}$ & $\begin{array}{c}\text { Interval } \\
\text { Outlet T }\left({ }^{\circ} \mathbf{C}\right)\end{array}$ & $\begin{array}{c}\text { Cold } \\
\text { Stream }\end{array}$ & $\begin{array}{c}\mathrm{FCp} \\
\left(\mathbf{k W} /{ }^{\circ} \mathbf{C}\right)\end{array}$ & $\begin{array}{c}\text { Interval } \\
\text { Inlet T }\left({ }^{\circ} \mathbf{C}\right)\end{array}$ & $\begin{array}{c}\text { Interval } \\
\text { Outlet } \mathbf{~}\left({ }^{\circ} \mathbf{C}\right)\end{array}$ \\
\hline H1 & 0.15 & $230-260$ & $30-50$ & $\mathrm{C} 1$ & 0.20 & $10-40$ & $170-190$ \\
H2 & 0.50 & $135-155$ & $110-150$ & $\mathrm{C} 2$ & 0.30 & $90-110$ & $180-225$ \\
H3 & 0.25 & $80-100$ & $20-30$ & $\mathrm{C} 3$ & 0.15 & $125-160$ & $225-235$ \\
H4 & 0.30 & $110-120$ & $80-100$ & $\mathrm{C} 4$ & 0.40 & $130-150$ & $250-280$ \\
\hline
\end{tabular}

Price of Steam: $80 \$ \cdot k g / k W$

Price of Cooling Water: $20 \$ \cdot \mathrm{kg} / \mathrm{kW}$

\begin{tabular}{|c|c|c|c|c|c|c|c|}
\hline \multicolumn{8}{|c|}{ Test Problem 4 (Non lineal): Non-Isothermal, 3 hot and 3 cold streams } \\
\hline $\begin{array}{c}\text { Hot } \\
\text { Stream }\end{array}$ & $\begin{array}{c}\mathrm{FCp} \\
\left(\mathrm{kW} /{ }^{\circ} \mathrm{C}\right)\end{array}$ & $\begin{array}{c}\text { Interval } \\
\text { Inlet } \mathrm{T}\left({ }^{\circ} \mathrm{C}\right)\end{array}$ & $\begin{array}{c}\text { Interval } \\
\text { Outlet } \mathrm{T}\left({ }^{\circ} \mathrm{C}\right)\end{array}$ & $\begin{array}{c}\text { Cold } \\
\text { Stream }\end{array}$ & $\begin{array}{c}\text { FCp } \\
\left(k W /{ }^{\circ} \mathrm{C}\right)\end{array}$ & $\begin{array}{c}\text { Interval } \\
\text { Inlet } \mathrm{T}\left({ }^{\circ} \mathrm{C}\right)\end{array}$ & $\begin{array}{c}\text { Interval } \\
\text { Outlet } \mathrm{T}\left({ }^{\circ} \mathrm{C}\right)\end{array}$ \\
\hline H1 & 0.15 & $180-200$ & $30-50$ & $\mathrm{C} 1$ & 0.20 & $15-25$ & $170-190$ \\
\hline $\mathrm{H} 2$ & 0.50 & $120-140$ & $75-95$ & C2 & 0.30 & $110-140$ & $225-235$ \\
\hline H3 & 0.10 & $110-155$ & $90-100$ & C3 & 0.15 & $70-100$ & $140-150$ \\
\hline
\end{tabular}

Price of Steam: $80 \$ \cdot \mathrm{kg} / \mathrm{kW}$

Price of Cooling Water: $20 \$ \cdot \mathrm{kg} / \mathrm{kW}$ 
Table 4

\begin{tabular}{|c|c|c|c|c|c|}
\hline \multicolumn{6}{|c|}{ Optimal Solution Test Problem 2: Non-Isothermal, 3 hot and 3 cold streams } \\
\hline \multirow{2}{*}{ Stream } & \multirow{2}{*}{$\begin{array}{c}\text { FCp } \\
\left(k W /{ }^{\circ} \mathrm{C}\right)\end{array}$} & \multicolumn{2}{|c|}{ G.Y.K. Model } & \multicolumn{2}{|c|}{ Present work } \\
\hline & & $\begin{array}{l}\text { Opt Inlet } \\
\text { Temp }\left({ }^{\circ} \mathrm{C}\right)\end{array}$ & $\begin{array}{l}\text { Opt Outlet } \\
\text { Temp }\left({ }^{\circ} \mathrm{C}\right)\end{array}$ & $\begin{array}{l}\text { Opt Inlet } \\
\text { Temp }\left({ }^{\circ} \mathrm{C}\right)\end{array}$ & $\begin{array}{l}\text { Opt Outlet } \\
\text { Temp }\left({ }^{\circ} \mathrm{C}\right)\end{array}$ \\
\hline $\mathrm{H} 1$ & 0.15 & 260.00 & 50.00 & 260.00 & 50.00 \\
\hline $\mathrm{H} 2$ & 0.50 & 210.00 & 95.00 & 210.00 & 95.00 \\
\hline $\mathrm{H3}$ & 0.10 & 110.00 & 100.00 & 110.00 & 100.00 \\
\hline $\mathrm{C} 1$ & 0.20 & 15.00 & 190.00 & 15.00 & 190.00 \\
\hline $\mathrm{C} 2$ & 0.30 & 110.00 & 225.00 & 110.00 & 225.00 \\
\hline C3 & 0.15 & 70.00 & 150.00 & 70.00 & 150.00 \\
\hline \multicolumn{6}{|c|}{ Optimal Solution Test Problem 3: Non-Isothermal, 4 hot and 4 cold streams } \\
\hline $\mathrm{H} 1$ & 0.15 & 260.00 & 50.00 & 260.00 & 50.00 \\
\hline $\mathrm{H} 2$ & 0.50 & 155.00 & 120.50 & 155.00 & 126.50 \\
\hline $\mathrm{H} 3$ & 0.25 & 80.00 & 30.00 & 80.00 & 30.00 \\
\hline $\mathrm{H} 4$ & 0.30 & 110.00 & 100.00 & 120.00 & 100.00 \\
\hline $\mathrm{C} 1$ & 0.20 & 10.00 & 170.00 & 10.00 & 170.00 \\
\hline $\mathrm{C} 2$ & 0.30 & 90.00 & 180.00 & 90.00 & 180.00 \\
\hline $\mathrm{C} 3$ & 0.15 & 160.00 & 225.00 & 160.00 & 225.00 \\
\hline $\mathrm{C} 4$ & 0.40 & 150.00 & 250.00 & 150.00 & 250.00 \\
\hline
\end{tabular}

Optimal Solution Test Problem 4 (Non lineal): Non-Isothermal, 3 hot and 3 cold streams

\begin{tabular}{cc|cc|cc} 
H1 & 0.15 & 196.00 & 41.50 & 196.00 & 41.50 \\
$\mathrm{H} 2$ & 0.50 & 135.00 & 90.00 & 130.00 & 90.00 \\
$\mathrm{H} 3$ & 0.10 & 131.50 & 94.75 & 136.50 & 94.75 \\
\hline $\mathrm{C} 1$ & 0.20 & 18.00 & 172.00 & 18.00 & 172.00 \\
$\mathrm{C} 2$ & 0.30 & 137.00 & $225 . .00$ & 137.00 & 225.00 \\
$\mathrm{C} 3$ & 0.15 & 89.75 & 140.00 & 84.75 & 140.00
\end{tabular}


Table 5

\begin{tabular}{|c|c|c|c|c|c|c|}
\hline \multirow[b]{2}{*}{ RESULTS } & \multicolumn{2}{|c|}{ Test Problem 2} & \multicolumn{2}{|c|}{ Test Problem 3} & \multicolumn{2}{|c|}{ Test Problem 4} \\
\hline & $\begin{array}{l}\text { G.Y.K. } \\
\text { Model }\end{array}$ & $\begin{array}{c}\text { Present } \\
\text { work }\end{array}$ & $\begin{array}{l}\text { G.Y.K. } \\
\text { Model }\end{array}$ & $\begin{array}{c}\text { Present } \\
\text { work }\end{array}$ & $\begin{array}{l}\text { G.Y.K. } \\
\text { Model }\end{array}$ & $\begin{array}{c}\text { Present } \\
\text { work }\end{array}$ \\
\hline Initial Problem & & & & & & \\
\hline № Equations & 416 & 3047 & 730 & 5375 & 416 & 3047 \\
\hline № Variables & 171 & 1247 & 291 & 2125 & 171 & 1247 \\
\hline № Binary Variables & 108 & 216 & 192 & 307 & 108 & 169 \\
\hline Reduced MIP Proble & & & & & & \\
\hline № Equations & 225 & 839 & 142 & 675 & 92 & 416 \\
\hline № Variables & 92 & 329 & 68 & 283 & 46 & 174 \\
\hline CPU time (sec)* & 0.453 & 0.749 & 0.108 & 0.218 & 0.678 & 3.332 \\
\hline Heating Req. (kW/kg) & 0.00 & 0.00 & 49.50 & 49.50 & 28.900 & 29.250 \\
\hline Cooling Req. (kW/kg) & 8.50 & 8.50 & 5.00 & 5.00 & 12.763 & 11.113 \\
\hline Optimal Solution (\$) & 170.00 & 170.00 & 4060.00 & 4060.00 & 2918.625 & 2903.625 \\
\hline $\begin{array}{l}\text { Solution of Relaxed } \\
\text { Problem }\end{array}$ & 0.00 & 0.00 & 620.00 & 3124.02 & 767.00 & 1904.725 \\
\hline GAP (\%) & 100.00 & 100.00 & 84.7 & 23.1 & 73.7 & 34.4 \\
\hline
\end{tabular}

* Pentium Dual-Core E5300 2.60GHz, using CPLEX 12.4.0.0 for MILP 
Table 6

\begin{tabular}{|c|c|c|c|c|}
\hline & \multicolumn{4}{|c|}{ PROBLEM COLUMNS: Pressure range: 1 - 3atm } \\
\hline & Stream & $\mathrm{FCp}\left(\mathrm{kW} /{ }^{\circ} \mathrm{C}\right)$ & Inlet Temp $\left({ }^{\circ} \mathrm{C}\right)$ & Outlet Temp $\left({ }^{\circ} \mathrm{C}\right)$ \\
\hline \multirow[b]{2}{*}{ Column 1} & H1 (Condenser) & $292.95-381.18$ & $95.95-136.07$ & $89.46-130.08$ \\
\hline & C1 (Rohoiler) & 201 56211 & $15767-20336$ & $16234-20772$ \\
\hline \multirow{3}{*}{ Column 2} & H2 (Condenser) & $1102.01-1242.24$ & $77.47-116.30$ & $76.47-115.30$ \\
\hline & & & & \\
\hline & C2 (Reboiler) & $1121.98-1263.15$ & $117.64-159.51$ & $118.64-160.51$ \\
\hline \multirow{3}{*}{ Column 3} & H3 (Condenser) & $1621.92-1812.95$ & $136.18-180.17$ & $135.18-179.17$ \\
\hline & & & & \\
\hline & C3 (Reboiler) & $1642.63-1834.28$ & $173.60-220.67$ & $174.60-221.674$ \\
\hline
\end{tabular}

Price of Steam: $80 \$ \cdot \mathrm{kg} / \mathrm{kW}$

Price of Cooling Water: $20 \$ \cdot \mathrm{kg} / \mathrm{kW}$

Table 7

\begin{tabular}{lcc}
\multicolumn{2}{c}{ Results Problem COLUMNS } & \\
& G.Y.K. Model & Present work \\
\hline No Equations & 467 & 3068 \\
No Variables & 232 & 1283 \\
No Binary Variables & 108 & 207 \\
CPU time (sec)* & 0.81 & 1.50 \\
\hline & C1: 1.000 & C1: 1.000 \\
\hline Columns Pressure (atm) & C2: 1.893 & C2: 1.000 \\
\hline Heating Req. (kW/kg) & C3: 1.919 & C3: 1.926 \\
\hline Cooling Req. (kW/kg) & 3267.36 & 3204.36 \\
\hline Optimal Solution (\$) & 3067.30 & 3004.72 \\
\hline
\end{tabular}

* Pentium Dual-Core E5300 2.60GHz, using DICOPT for MINLP 
Table 8

\begin{tabular}{c|c}
\hline Component & Feed (kmol/h) \\
\hline $\mathrm{N}_{2}$ & 105.50 \\
$\mathrm{C}_{1}$ & 4139.00 \\
$\mathrm{C}_{2}$ & 435.50 \\
$\mathrm{C}_{3}$ & 205.50 \\
$\mathrm{nC}_{4}$ & 70.50 \\
$\mathrm{nC}_{5}$ & 28.50 \\
$\mathrm{nC}_{6}$ & 16.50 \\
\hline $\mathrm{Total}$ & 5000.00
\end{tabular}


Table 9

\begin{tabular}{|c|c|c|}
\hline & Problem Limits & Solution \\
\hline Streams & Temperature Range (K) & Temperature (K) \\
\hline In HExc1 & $361-361$ & 361 \\
\hline Out HExc1 & $303-343$ & 343 \\
\hline In HExc2 & $303-343$ & 343 \\
\hline Out HExc2 & $203-253$ & 223.10 \\
\hline In HExc3 & $203-253$ & 223.10 \\
\hline Out HExc3 & $273-333$ & 333 \\
\hline In HExc4 & $203-253$ & 223.10 \\
\hline Out HExc4 & $273-333$ & 329.71 \\
\hline \multicolumn{3}{|c|}{ Restrictions } \\
\hline $\begin{array}{l}\text { Molar Flow Light Product } \\
(\mathrm{kmol} / \mathrm{h})\end{array}$ & $>4930$ & 4954.67 \\
\hline $\begin{array}{l}\text { Molar Frac. (nC4 + lighter) in } \\
\text { Light Product }\end{array}$ & $>0.995$ & 0.998 \\
\hline $\begin{array}{l}\text { Molar Flow Heavy Product } \\
(\mathrm{kmol} / \mathrm{h})\end{array}$ & $>35$ & 45.33 \\
\hline $\begin{array}{l}\text { Molar Frac. }(n C 5+n C 6) \text { in } \\
\text { Heavy Product }\end{array}$ & $>0.75$ & 0.75 \\
\hline
\end{tabular}

Solution Parameters

№ Equations

№ Variables

№ Binary Variables

Iterations

Heat Solution

Heating Req. (kW)

0.0

Cooling Req. (kW)

1740.2

Optimal Solution (KW)
290

195

116

68 